\title{
Review
}

\section{Gene silencing by double-stranded RNA}

\author{
Nobel Lecture, December 8, 2006 \\ by $\mathbf{A Z}$ Fire ${ }^{1,2}$
}

\begin{abstract}
Thanks to the Nobel Foundation for permission to publish this Lecture (Copyright $\mathbb{C}$ The Nobel Foundation 2006). We report here the Nobel Lecture delivered by Professor Andrew Z Fire. Together with the accompanying lecture by Professor Mello this lecture describes the exciting years leading to the discovery of RNA interference (RNAi) and some of the underlying molecular mechanisms. Professor Fire nicely points out his own contribution and the contribution of other research groups to the development of this field. He also presents an interesting discussion on the role of RNAi in immunity and challenges us with a number of open questions. The lecture ends presenting the great potential of exploiting RNAi for therapeutical purposes.
\end{abstract}

Cell Death and Differentiation (2007) 14, 1998-2012; doi:10.1038/sj.cdd.4402253

I would like to thank the Nobel Assembly of the Karolinska Institutet for the opportunity to describe some recent work on RNA-triggered gene silencing. First a few disclaimers, however. Telling the full story of gene silencing would be a mammoth enterprise that would take me many years to write and would take you well into the night to read. So we will need to abbreviate the story more than a little. Second (and as you will see), we are only in the dawn of our knowledge; so consider the following to be a primer... the best we could do as of December 8th, 2006. And third, please understand that the story that I am telling represents the work of several generations of biologists, chemists, and many shades in between. I am pleased and proud that work from my laboratory has contributed to the field, and that this has led to my being chosen as one of the messengers to relay the story in this forum. At the same time, I hope that there will be no confusion of equating our modest contributions with those of the much grander RNA interference (RNAi) enterprise.

\section{Double-Stranded RNA as a Biological Alarm Signal}

These disclaimers in hand, the story can now start with a biography of the first main character. Double-stranded RNA (dsRNA) is probably as old (or almost as old) as life on earth. Scientific recognition of this form of RNA is, however, a bit more recent, dating from the mid 1950s. The same kinds of base pairs of that can zip strands of DNA into a helix ${ }^{1}$ were recognized just a few years later as being a feature of RNA structure. $^{2-5}$ When two RNA strands have extended regions of complementary sequence, they can zip together to form a somewhat flexible rod-like structure similar in character (but distinct in detail ${ }^{5,6}$ ) from that of the DNA double helix. The occurrence of dsRNAs in biological systems was uncovered in a number of experiments in the early 1960 s. $^{7-9}$ Intriguingly, all of the biological systems initially found to be sources for dsRNA involved virus infection. These data supported a proposal that many viruses might replicate from RNA to RNA through a dsRNA intermediate. At the time, the central dogma of molecular biology was being experimentally established, giving a clear indication that cells mainly used 199 dsDNA and single-stranded RNA for longand short-term information storage, respectively. This left no place in normal cellular information flow for dsRNA, while leaving a key role (at least transiently) for dsRNA in replication of RNA viruses.

Our story next jumps back almost 30 years to a set of experiments that was directed toward an understanding of host-cell responses to viral infection. ${ }^{10,11}$ These experiments involve two different (essentially unrelated) viruses infecting a single host. One virus was quite virulent and would kill its unfortunate host animal, while the second virus was relatively benign, causing only minor symptoms. The surprising result was that a preliminary infection with the benign virus could provide resistance to a subsequent challenge by the more virulent, nasty virus. The conclusion from these results is that the host (a rabbit in this case) has a way of knowing that it has been challenged by a viral pathogen and somehow sends itself a signal allowing resistance to further challenge. Although the ability of viruses to induce immune responses

${ }^{1}$ Department of Pathology, Stanford University School of Medicine, Stanford, CA, USA and ${ }^{2}$ Department of Genetics, Stanford University School of Medicine, Stanford, CA, USA

Correspondence: G Melino, Cell Death and Differentiation, Rome Editorial Office, D26, University Rome Tor Vergata, via Montpellier 1, 00133-Rome, Italy.

Email: cell.death.differ@uniroma2.it

Keywords: RNAi; siRNA; gene therapy; immunity; cancer; transcription 
had been known for a long time, these results were unexpected by virtue of the apparent lack of relatedness between the two viruses used in the experiment. The generalized response to infection was a new phenomenon and led to an understanding of immune mechanisms that involve general alarm responses. A key follow-up to this observation was made about 20 years later when Isaacs and Lindeman $^{12}$ actually separated a protein component from the challenged animals that could transfer the general viral resistance when injected into naive animals. That protein component was called interferon.

In the course of this analysis, a physician/scientist named Richard Shope became interested in applying the innate immune response by finding treatments that would induce generalized immunity to provide viral resistance. Traveling the world at the end of the second world war, he collected biological materials looking for something that could be ground up and used as a starting material. His most notable success came from a fungus (Penicillium funiculosum) that he found in Guam growing on a picture of his wife Helen. Calling the extracts of the fungus 'Helenine', Shope found that these could induce an interferon response in animals. ${ }^{13}$

A next chapter in this early story was carried out by Maurice Hilleman's group at Merck, who used Shope's fungus as a starting point to purify the material that was actually responsible for the viral resistance. In a paper published in $1967,{ }^{14}$ they showed that dsRNA was present in the fungal extracts and was responsible for the induction of resistance. Given that there would have been little or no sequence similarity between the fungus-derived dsRNA and the viral target, they then tested additional very distantly related natural and synthetic dsRNAs and found that all could induce an interferon response. ${ }^{15-17}$ There were (of course) many different questions raised by this study. Paramount perhaps was the question of why dsRNA was present in the fungus. Hilleman's publications suggested the intriguing hypothesis that it was due to a fortuitous viral infection of the fungus. In fact, they had discovered an ancient system by which cells could sense a molecule that was a bellwether of viral infection (dsRNA) and respond by producing a signal that would tell the organism to dedicate its efforts and energies toward fighting viruses.

Early studies of systemic immunity were by no means limited to animal cells. Even as the first observations of an 'interferon' response in animals were made in the 1930s, it had already been observed that plants could induce some remarkable immune responses. Applying a virus in one area of a plant could yield viral resistance (at least in some cases) that extended throughout the plant. ${ }^{18,19}$ Although these experiments indicated that plants had an immune system, it was known that they lacked the specific immune components (including antibodies and white blood cells) that had been studied for many years in animals.

This historical context of the gene-silencing field thus includes the early recognition of an animal immune response (albeit a general one) dependent on dsRNA, and a plant immune response (albeit with trigger unknown) that could disseminate a specific signal over substantial biological distances.

\section{Gene Silencing Assays in a Convenient Nematode}

Now it is time to introduce another lead character into our story, one that is a close friend to Craig, myself, and to a few thousand other researchers worldwide. Caenorhabditis elegans is a nematode roundworm about $1 \mathrm{~mm}$ in length. In this lecture series, there were three talks on C. elegans in 2002 by Sydney Brenner, John Sulston, and Bob Horvitz. Dr Brenner credited 'the worm' as deserving a significant portion of the scientific accolades (although he was reluctant to provide a monetary share to the worm) ${ }^{20}$ We should certainly credit this beast as well: $C$. elegans has turned out to be a very fortunate choice for studies of gene silencing. As you will see, the worm's vehement responses to foreign information have provided first great frustration and later some valuable insights.

One of the aspects of $C$. elegans that Craig and I have been very pleased with is the ability to microinject macromolecules (DNA, RNA, protein) into the animal. ${ }^{21-25}$ Figure 1 is a picture that Craig took of this process, showing a fine glass needle injecting solution into an animal. After the needle pierces the cuticle, pressure is applied and some of the fluid comes into the cell that is being filled. The cell being injected in this photo is the germline or gonad of the worm, a large cell with hundreds of individual nuclei surrounding a common core of cytoplasm. Each gonad will generate hundreds of oocytes, making this is a remarkable technique for being able to influence a large population of animals with just a single microinjection. The microinjection needle can be filled with almost any liquid including the great variety of DNAs, RNAs, and proteins that we can now design and synthesize in the lab. The simplicity of microinjection for $C$. elegans provided an enticing experimental tool to manipulate the genome of the organism and observe the consequences to developmental events and physiology. At the same time, this technology has allowed a number of us in the field to study the diverse responses this system has to foreign information. Among the goals pursued in early applications of $C$. elegans microinjection was to turn down or turn up gene expression for specific genes. In the mid 1980s, as a Helen Hay Whitney Fellow working at the Medical Research Council Lab of Molecular Biology, in Cambridge UK, I had begun doing experiments toward this goal, using among other tools the unc-22 gene that provided some of the first characterized DNA clones for the worm. It was already known through some very nice classical genetics that reducing expression of unc-22 led to a

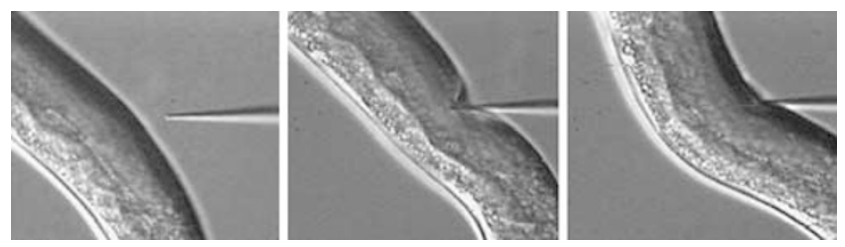

Figure 1 Micrograph of microinjection needle delivering a solution of DNA to the gonad of a Caenorhabditis adult hermaphrodite. Left: microinjection needle poised at the side of the worm. The needle is filled with a solution for injection and is kept under a slight positive pressure until it is inserted into an animal (middle) whereupon an increase in pressure leads to microinjection of a volume of the material from the needle. After this, the needle is removed and the cuticle of the animal quickly recovers. Photographs courtesy of Dr. Craig C Mello and reprinted from Mello and Fire $^{25}$ 
movement defect, a twitching behavior that is very characteristic of alterations in the activity of this gene. ${ }^{26,27}$ Don Moerman, Guy Benian, and Bob Waterston prepared fragments of unc- $22^{28}$ that I then injected with the hope that the injected fragments might recombine with the normal unc-22 allele and produce a loss-of-function character that could then be studied. The results of these experiments were a puzzle: although twitching worms appeared in populations derived from the injected animals, there was no direct alteration in the original unc-22 gene. Instead of the sought-after recombination event, it appeared that the presence of extra DNA from the unc-22 locus could induce the worm to turn down expression of the endogenous unc-22 gene. ${ }^{29}$ Several explanations for this unusual suppression effect seemed reasonable at the time: perhaps the endogenous unc-22 locus DNA somehow paired with the foreign copies of this DNA; perhaps the foreign DNA was a template for synthesis of some amount of antisense RNA, which would then neutralize the activity of the normal transcript by base pairing; perhaps the fragments of unc-22 were producing an aberrant protein or binding an essential regulatory factor; and perhaps there were some other mechanisms that were yet to be recognized. Regardless of the actual mechanism of the interference in these initial experiments, the antisense strategy for 'targeted' disruption of gene expression seemed particularly worthy of an explicit test. Such strategies were by no means novel at the time, having been pioneered some years earlier by Zamecnik and Stephenson, ${ }^{30}$ and by Izant and Weintraub. ${ }^{31}$ In 1987 , just after moving to the Carnegie Institution in Baltimore, my co-worker Susan White-Harrison began to build DNA constructs to perform such an explicit test. Susan's constructions relied on our ongoing elucidation of muscle promoters (DNA sequences that instruct RNA polymerase to begin RNA synthesis in muscle cell nuclei). We expected a promoter hooked up to an unc-22 fragment in the 'antisense' orientation to give antisense RNA and thus perhaps gene silencing, while the corresponding 'sense' construct would give at most an excess of the sense strand and thus no expected silencing. We were hardly surprised when the antisense constructs produced a targeted interference effect (knockdown of the corresponding endogenous gene). This was consistent with a substantial number of reports of successful antisense intervention already in the literature. We were very surprised, however, when the control 'sense' constructs produced a similar interference effect. ${ }^{32,33}$ The assumption for the 'experimental' construct was that the antisense RNAs were finding their sense equivalents by standard Watson-Crick base pairing and taking the sense RNAs out of circulation. So what was going on with the sense constructs (where if anything, we might expect the fragment inserted into the expression vector to be overexpressed?). Although this mystery was intriguing, it was hardly compelling at the time. The propensity for DNA transgenes to produce unwanted RNA transcription was certainly a good starting point for potential models, and a reasonable explanation (that somewhat dampened any immediate research on our part) would have been that the transgenes for some reason produced sufficient antisense RNA to yield an interference effect.

A significant milestone in the study of silencing in $C$. elegans was the demonstration that direct RNA injection could induce an interference effect. ${ }^{34}$ This observation came from work of $\mathrm{Su}$ Guo, who at the time was a graduate student in Ken Kemphues' lab at Cornell. Sue's insight that injection of RNA might provoke silencing turned out to be correct. Moreover, she was able to demonstrate effects with either sense or antisense preparations of RNA. This set of experiments had two lessons. First, the experiments established a remarkably efficient means of disrupting gene activity (particularly in embryos), thus facilitating a wealth of experiments in what we now call functional genomics (efforts to assign function to genes that are discovered by large scale sequencing). Second, the mystery of the interfering sense preparations was accentuated since 'sense' RNA preparations could still trigger an interference response.

After Su's experiments established RNA-triggered silencing as both a mystery and a powerful technique for studying gene function in the embryo, several other groups started working with the technique and marveling at its unusual character. Craig Mello, first as a postdoctoral fellow working with Jim Priess at the Fred Hutchinson Cancer Research Center, and then as a new faculty member at the University of Massachusetts, began in particular to apply the technique ${ }^{35}$ and to study the phenomenon as a window on a fascinating fragment of the tapestry of biological regulation. As I will describe later, a significant advance in understanding the concerted nature of the response came when Sam Driver and Craig discovered that the silencing could be evoked by a diffusible and specific molecular signal. As the experience from Craig's group and others with this odd form of gene silencing accumulated, much of the information was shared with the $C$. elegans community. Although the name 'antisense' had initially been used to describe this process, it was clear (from the 'sense' results) that the phenomenon was not a simple one of antisense occlusion. There was thus a need for a new designation for the process, and after putting a few potential names to a vote, Craig chose the term 'RNAi' to refer to the observed silencing process(es). ${ }^{35}$

\section{Toward a Structural Understanding of the RNAi Trigger}

For my perspective at the time (at that point as an observer of work in other labs on the worm's response to injected RNA), much of the accumulating data came together at an informal discussion on RNA-triggered silencing organized by Craig at the 1997 C. elegans meeting in Madison, Wisconsin. The workshop was held in the theater of the Student Union, with the normal capacity of the room overwhelmed (I was sitting on the floor). At the time, there were several very clear but also very unexplained features of the response. In addition to the diffusible signaling data (reported by Driver at the previous year's $C$. elegans meeting), and the ability of both sense and antisense strands to produce the interference effect, there was a remarkable persistence to the effect. From work of Craig, Rueyling Lin, Morgan Park, and Mike Krause, and from Patty Kuwabara, ${ }^{36}$ it was clear that injected RNAs could have effects for several days after the injection occurred (and in some cases generations after the initial injections). This contrasted with observations that Geraldine Seydoux had made several years earlier, ${ }^{37}$ showing that many native RNAs were comparatively unstable during the same time period in 
the same cells. The confluence of these two results suggested perhaps that the active interfering material had some kind of a privilege in its stability. Perhaps the injected material contained a fraction of particularly stable molecules that were responsible for the persistent interference.

dsRNA was known to be relatively stable both chemically and enzymatically. ${ }^{38}$ In addition, dsRNA was a known low level contaminant in synthetic RNA preparations. ${ }^{39}$ From my graduate work with RNA polymerases, I was certainly also very familiar with the sometimes annoying ability of RNA polymerases to start in vitro at ends and other fortuitous sites. Thus the concept that dsRNA might be a component of the injected material was hardly a leap of logic. Arguing strongly against dsRNA as a potential effector was the fact that native dsRNA would have no free base pairs to interact with matching molecules in the cell. Thus, a rational first guess would have been that injected dsRNA would have been unable to interact specifically with cognate sequences and thus rather useless for triggering genetic interference. A critical review of my research plan coming out of the 1997 worm meeting would certainly have brought this up as a major concern. One could imagine (in retrospect as well as currently) many different models and explanations for the phenomena. Some scenarios would have spawned interesting experimental investigations, while others would have been of only limited interest; I was certainly fortunate that our research grant was not up for renewal for at least a few months.

The strength of the experimental system with $C$. elegans was that virtually any biochemical sludge could be concocted and injected into a worm, with a very rapid (and in most cases quite specific) assay at the end for targeted genetic modulation. This made it possible to test somewhat far-fetched hypotheses (like the involvement of dsRNA) without spending years or 'breaking the bank'. A second ingredient in testing the dsRNA was someone to make the experiments happen. SiQun Xu, with extensive experience with both nucleic acid synthesis and isolation and with $C$. elegans microinjection, was certainly the ideal person for this for many reasons. The setup was particularly comfortable for me, since SiQun could thus do the syntheses and injections, and I just needed to visit my microscope in the lab for an hour or two every day to look at the injected animals and their progeny.

SiQun first repeated the kinds of RNA synthesis reactions and injections that others had done, using in this case our favorite gene, the $C$. elegans unc-22 gene. This of course worked, generating a bunch or twitching worms as evidence for effective silencing of endogenous unc-22 activity and setting the stage to use this assay in characterizing the relationship between structure and interference of the injected RNA. The picture shown in Figure 2 shows a series of the initial RNA preparations resolved using an electrophoretic field and an agarose gel. What you can see is a very prominent band, a bright spot, where the RNA that we expected was. This photo was deliberately overexposed to reveal any other components that might be present, and one can certainly see additional (minor) bands and a general 'smear' in addition to the major (expected) bands. After a few preliminary explorations of the dsRNA hypothesis using this assay with these impure RNA preparations, I was somewhat encouraged but still by no means convinced. It was clear that a cleaner

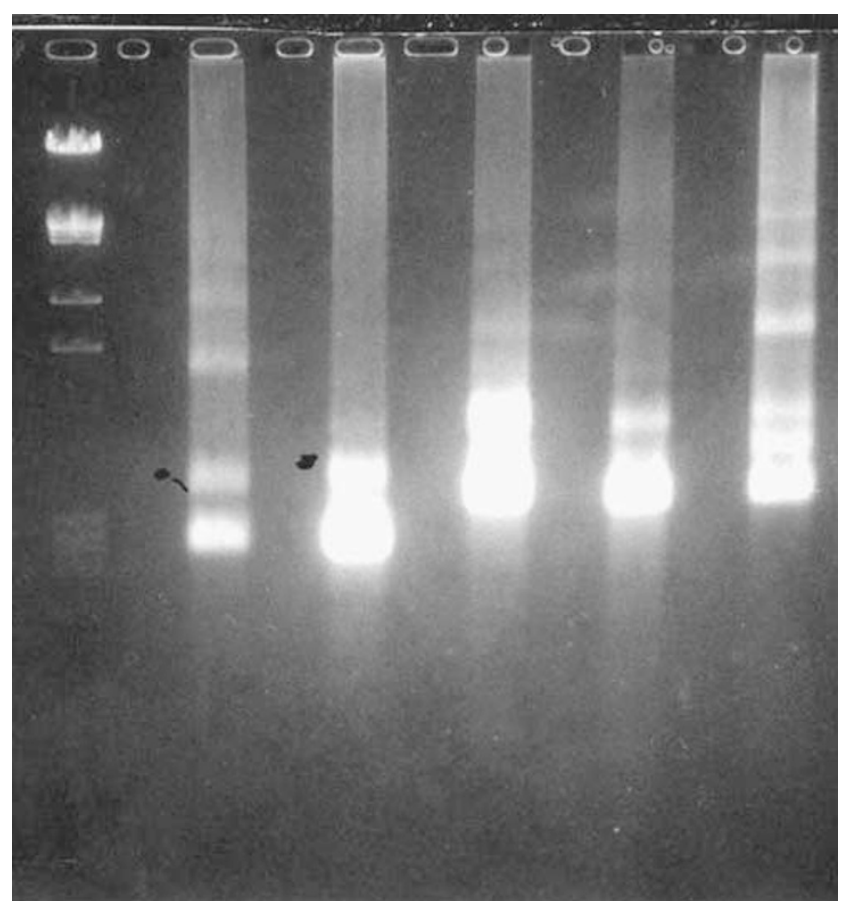

Figure 2 Electrophoretic separation of RNA prepared by in vitro synthesis. Left lane: marker DNAs. Remaining lanes show RNA populations with a strong band (bright signal) in the expected position for single-stranded sense or antisense RNA (depending on the intended synthesis) and a number of unexpected bands (and a smear) in each lane that is visible due to overexposure of the photograph. RNA is resolved on agarose gels and visualized by fluorescence upon interaction with the included dye Ethidium Bromide. Source: Original Gel Photograph, SiQun Xu and Andrew Fire, 1997

preparation of starting material was needed. To achieve this, SiQun cut out the major bands from this gel, extracted the RNA, and injected the purified sense or antisense RNAs into worms. This produced a result, albeit negative: almost all of the activity was lost by purification of single strands, suggesting that the sense and antisense weren't the material that was causing the interference.

SiQun's purified strands also provided a better starting point for testing the dsRNA hypothesis, since the two nearly inactive strands could be mixed in a test tube to produce a well-defined double-stranded product. SiQun's injection of doublestranded unc-22 RNA formed in this way produced a remarkable result, with all of the resulting animals twitching strongly. To see how potent the effect was, SiQun injected smaller and smaller amounts of the double-stranded material (Figure 3). The resulting animals showed an interference effect even after substantial dilution. When we finally did the calculation of how much material was being injected, we realized that we were seeing effects down to a few molecules of the dsRNA per cell. This was remarkable in that we knew from some previous work that we and Don Moerman and others had done that the target unc-22 mRNA was much more abundant.

As with any uncharted phenomenon, the first job of the scientist is to look for explanations based on known processes. The summer of 1997 was a busy one for phone lines, email connections, and delivery services between 
Baltimore and Worcester, with numerous collaborative experiments with Craig and SiQun now joined by Steve Kostas and Mary Montgomery. In addition to the characterization of the specificity/generality/character of the effect on target genes, a major goal was to definitively ask whether dsRNA in the interfering sequence was directly responsible for the observed effects. An alternative explanation was still quite tenable: that dsRNA produced a nonspecific response (either local or global) that potentiated the activity of small amounts of antisense. Settling this issue took a bit of molecular artistry to pursue. The most satisfying were a set of assays where we could look at gene-specific interference by complex RNA molecules that contained single-stranded RNA matching one gene and dsRNA matching a second gene. All of these experiments pointed clearly to induction of specific interference by regions of dsRNA, and by the end of the summer we all felt that a paper could be submitted definitively describing the ability of dsRNA to trigger a gene-specific and systemic silencing process. ${ }^{40}$

\section{dsRNA-Triggered Silencing Processes and Their Roles:} Lessons from Worms, Plants, Flies, Fungi, and Other Sundry Beasts

But of course we still did not know what was actually going on, in particular what was actually happening to the expression of the target gene. Mary Montgomery was certainly in an excellent position to pursue this question, having spent several years working around the apparent reluctance of C. elegans to translate injected RNA. The idea of an RNA injection experiment with a dramatic consequence (albeit strange and unexpected) was certainly enticing, so she took

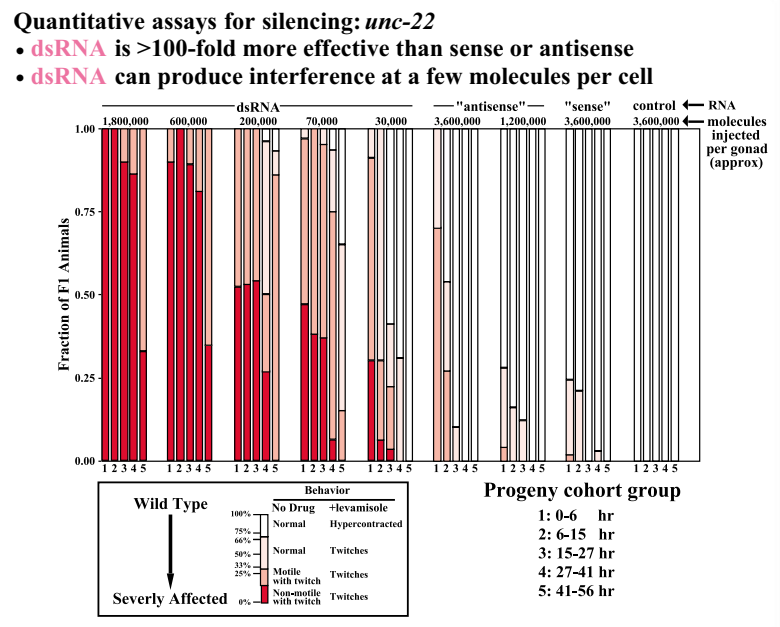

Figure 3 Quantitative assays for silencing of unc-22. Preparations of RNA similar to those in Figure 2 were enriched in the expected (sense or antisense) species by excising the major bands from agarose gels and extraction of RNA. Some unwanted dsRNA may persist in these samples, but in general at a greatly reduced level when compared to samples not subject to purification. Individual sections of the graph show biological responses following injection of differing concentrations of single- and dsRNAs as diagrammed below (more highly affected animals are shown with a more intense red color). Source: Fire et al..$^{40}$ Supplement; see reference also for additional details up the question of what happens to gene expression in the presence of injected dsRNA. At the time, one could imagine the interference affecting any step of gene expression or cellular homeostasis. Mary had observed that target genes lost their ability to accumulate mRNA in the cytoplasm. ${ }^{40}$ Extending this analysis, she was able to demonstrate that RNAi was accompanied by destabilization of the target mRNA in the nuclei and cytoplasms of infected cells. ${ }^{41}$ In some ways we were lucky to be working on one of the simpler dsRNA response systems; current knowledge of RNA-modulated gene expression has led to the realization that virtually every activity of genes can be affected by modulatory RNAs (replication, DNA structure and sequence, chromatin structure, transcription, processing, localization, ability to engage the translation machinery, and translational progression. ${ }^{42-48}$ Mary's experiments also provided a remarkable graphic description of the effectiveness of RNAi in C. elegans. Figure 4 shows an example of this, with a test gene examined with and without interference at the level of messenger RNA abundance. In the case of a control sample, the messenger RNA for this gene is highly abundant and readily detected by the color reaction derived from a procedure called in situ hybridization. ${ }^{49}$ After interfering with the test gene by injecting the corresponding dsRNA, the messenger RNA was essentially undetectable. The hypothesis that came from Mary's experiments was that the dsRNA produced a condition where the target transcript was produced but was very unstable. Restated, this postulates a sequence-specific RNA degradation system that could be triggered by dsRNA. An old TV show called 'the twilight zone' was based on the idea that the universe contains many phenomena that go beyond our capacity to understand. As of early 1998, the data we had accumulated were certainly consistent with the hypothesis that we were at least temporarily in the 'twilight zone'.

Accentuating this sense of unexplainable phenomena was a series of tests on the spatial requirements for dsRNA administration. These observations had a very rational starting point. When Su Guo did her original RNA injections at Cornell, she had intended to test for a biological effect of the injected material in the gonad. So she injected the gonad and indeed an effect was seen there. ${ }^{34}$ The science/life-lesson that one can draw from this is 'if you can do the experiment the way that seems most likely to be effective, do it just that way'.

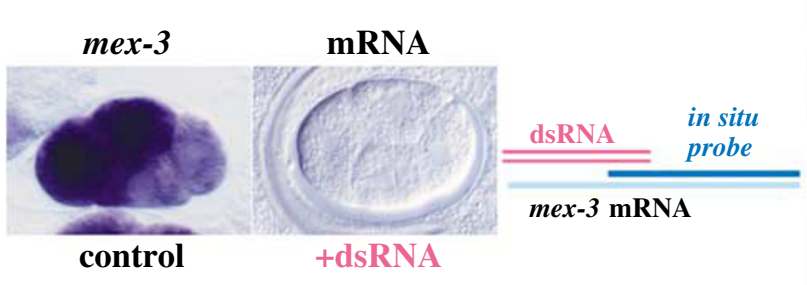

Figure 4 Injection of dsRNA results in disappearance of the targeted message. This experiment (from Mary Montgomery ${ }^{40}$ ) shows embryos of $C$. elegans with and without dsRNA injected corresponding to the mex-3 gene. ${ }^{142}$ In control samples, a strong signal is observed on in situ hybridization [AA] (intense blue stain, left panel), indicating a high level of mex-3 transcript throughout the four-cell embryo. Following dsRNA injection, the mex-3 transcripts are not detected (center panel) 
A subsequent observation from Sam Driver and Craig Mello, yields the lesson 'if you can not do the experiment the way that seems most likely to be effective, still do it'. In 1996, Sam was a beginning graduate student in Craig's lab at the University of Massachusetts. He was just starting out with injection and so putting the needle into the correct tissue was problematic. Sam and Craig realized that despite the improperly placed needles, the injections were still producing extremely efficient interference. When they then deliberately injected into the 'wrong' place (the body cavity), they still observed a strong biological effect. Later, Craig and SiQun Xu each extended this set of observations to an extensive list of tissues where dsRNA injection produced a systemic effect.

Finally, we have a third lesson, this time derived from experiments initiated by Lisa Timmons, then a postdoc in my lab at Carnegie and now a faculty member at Kansas University. The lesson here, if you are a postdoc or perhaps a graduate student, is to do experiments that your advisor would never condone or suggest. Lisa engineered Escherichia coli, which is a bacterium that is the food source for $C$. elegans, to produce dsRNA. When she fed this genetically modified food to the worm, she saw a gene-specific interference effect. Figure 5 shows a case where she had engineered the bacteria to make dsRNA corresponding to the fluorescent reporter GFP (a wonderful tool for following gene expression and cell patterns during development). ${ }^{50-52}$ Starting with a worm strain that produces GFP in essentially all somatic cells, Lisa found that the ingested RNA could silence gene expression throughout the animal. ${ }^{53}$ (The picture tells another interesting story, which is that there is considerable resistance to RNAi in nerves of the animal. Although we have yet to understand the basis or reason for this, the wholesale alteration in the efficacy of the pathway in different tissues provides additional evidence for a very deliberate biological process.) Hiroaki Tabara, a postdoctoral fellow working with Craig at the time, went even beyond the 'feeding' experiment, showing that simply soaking worms in dsRNA could produce an interference effect. ${ }^{54}$ These experiments were particularly surprising given our expectations that cell membranes would block all but the smallest diffusible molecules from moving between cells. We knew that there was little or no diffusion of DNA. A theme in macromolecular transport of large charged molecules has been that the cell transports only things that might be useful, with those transport mechanisms very specific and well controlled. I certainly had no idea of why the worm would be transporting dsRNA-derived signals in a facilitated manner.

So now we had every reason to think we were in 'the twilight zone'. Despite this, we were certainly pleased at our accomplishments in contributing to the development tools for manipulating gene expression in $C$. elegans. We now step through a doorway from the limited world of our favorite model organism to the much richer real world inhabited by species too numerous to count. This transition is accompanied by the recognition that discoveries that we may initially view as our technical 'accomplishments' are invariably a reflection of underlying processes that are a natural part of sustaining life.

Soon after the initial description of dsRNA-triggered silencing in $C$. elegans, several descriptions of similar processes appeared for other groups of organisms. These
Levels of (im)precision in RNA delivery

S. Guo (Cornell): RNA into gonad --> gonadal affect

S. Driver (UMass): RNA into body cavity --> gonadal affect

L. Timmons (Carnegie): Feed [dsRNA+ bacteria] to worms

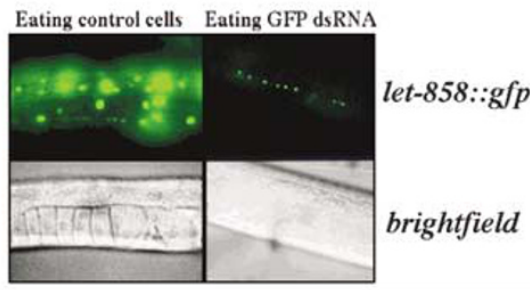

Figure 5 RNA delivered outside of a cell can produce a potent interference effect. Above, schematic diagrams of RNA delivery experiments from Su Guo and Ken Kemphues, ${ }^{34}$ Sam Driver and Craig Mello, ${ }^{40}$ and Lisa Timmons. ${ }^{53}$ Below are examples of feeding-based RNAi. Both animals are from a $C$. elegans strain where generalized somatic expression of a green fluorescent reporter is readily observed. The animal at the right is fed on bacteria expressing dsRNA corresponding to the gfp coding region. The animal on the left is fed on bacteria not expressing this construct. Note the dsRNA-dependent loss of gfp activity in this example in all visible cells except those of the nervous system

initially included observations from Drosophila (a fruit fly), Trypanosomes (single cell parasites), and plant systems, ${ }^{55-58}$ with many other organisms rapidly joining the list. Mammals were conspicuously absent from the initial list of organisms generally amenable to this type of manipulation. The exclusion of mammals from the list of easily manipulated species was not a surprise: the nonspecific responses to dsRNA that were originally discovered by Hilleman and colleagues ${ }^{14}$ were certainly sufficient to confound any analysis of specific genetic interference. Nonetheless, early efforts in this area provided both an indication of the potential existence of specific dsRNA responses in certain specialized mammalian cell systems (e.g. oocyte and ovary cells ${ }^{59-61}$ ) and of the predominance of the nonspecific response in most others. ${ }^{62}$

In addition to establishing a broader biological occurrence of dsRNA-triggered genetic interference, the demonstration of dsRNA-triggered silencing in plants and fungi illuminated the process by connecting our rather fragmentary observations from $C$. elegans with a broad gene silencing literature. Indeed, papers starting a decade earlier from fungal and plant systems had been the first to describe sequence-specific effects of foreign DNA transgenes on the corresponding endogenous genes ${ }^{63-67}$; also see Cameron and Jennings. ${ }^{68}$ Intensively creative work had allowed workers in both plant and fungal fields to track down the sequence-specific foreign DNA reactions as a complex set of responses that could independently attack the target gene's chromatin or RNA. ${ }^{46,69-71}$ The distinctive spatial patterns of silencing for endogenous genes in plants ${ }^{65,66}$ had been one of many features that had drawn a small cadre of highly innovative investigators to study this question for its own sake. Demonstrations of a systemic signal in plant silencing ${ }^{71,72}$ were particularly striking and certainly led to a clear recognition of 
potential similarities between the phenomena that had been observed in $C$. elegans and gene silencing in plants.

At this point, it is worth pointing out the substantial advantages of studying gene silencing (or any other important phenomenon) in more than one model system. The advantages of studying silencing in $C$. elegans turned out to be the flexibility of designing and making arbitrary RNA structures in a test tube and delivering them easily (by microinjection) into a rapid assay system (the nematode). This had circumvented many of the challenges faced by researchers working in plant systems, where such capabilities were not straightforward and complex issues of transgene structure and transcription confounded initial attempts to definitively assign a specific RNA structure as the trigger for the response. On the other side of the balance, plant systems offered a remarkable means to investigate the biological role of the interference response. Starting with the earliest recognitions of transgenederived viral resistance ${ }^{73}$ and observations that viral RNAs could be both triggers and targets for the silencing, ${ }^{46,74,75}$ it was rapidly clear that the silencing system might serve in the natural protection of plants from 'unwanted information' in the form of viral pathogens. Definitive demonstration of this point came from a number of analyses of virus/host interaction.

To be successful, one would expect a proposed antiviral system to effectively block pathogenesis of at least a subset of viruses that might otherwise menace the organism. Since it is well known that viruses still succeed in the world (much to our dismay), there must also be ways in which the virus can counteract any cellular defense mechanisms. A critical point in defining the role of the RNA-triggered silencing process was the recognition that many successful plant RNA viruses produce protein components dedicated to the inactivation of the silencing mechanism. ${ }^{76-79}$ Deliberate suppression of host-RNA-triggered silencing responses allows viral infectivity in at least a subset of plants for any given virus. The balance between the silencing mechanism and viral attempts to subvert it forms the basis for an ancient 'arms race' between virus and plant. The character of this arms race was further evidenced in these studies by the ability to generate attenuated virus (by removing the anti-silencing function) and hypersusceptible plants (by expressing a relevant viral anti-silencing protein or interfering with the endogenous RNAi machinery).

The emerging recognition that the transgene response mechanisms in plants were at least in part an antiviral response had raised the compelling question of how viral activity could be specifically recognized by a silencing apparatus. A rather remarkable proposal to explain this was put forth by Ratcliff, Harrison, and Baulcombe in mid 1997, ${ }^{80}$ in a paper that arrived at Carnegie just as we had scored our first assays to test for the ability of dsRNA to trigger gene silencing in $C$. elegans. Baulcombe and colleagues had reasoned that unique features of viral replication intermediates might lead to improved transgene-based triggers for gene silencing, stating 'It may be possible to increase the incidence of gene silencing by ensuring that transgene transcripts have features, such as double-strandedness, that resemble replicative forms of viral RNA' ${ }^{80}$ Combined with experiments suggesting an association between silencing effectiveness and certain secondary structures in the transgene and transcript, ${ }^{68,82}$ these proposals would almost certainly have inspired similar experiments to ours. The confluence of the two approaches, as always in science, proved to be the most powerful driver of further work, as the combination of chemical definition of the trigger in $C$. elegans and a biological explanation of its efficacy in plants led to a rapid explosion of scientific effort in the area.

\section{Towards a Reaction Mechanism: Efforts to Peer Inside the Black Box}

Despite the great enthusiasm from those of working with plant, worm, and insect model systems, the mechanism by which dsRNA could silence gene expression was still an unknown. Seminar slides made at the time would show dsRNA and the mRNA target somehow entering a large and mysterious 'black box', followed by degradation of the target RNA and some unknown fate for the effector dsRNA. This 'black box' explanation limited our grasp of the RNAi system, both for understanding the underlying biology and for applying RNAi to organisms (like humans) where the response to dsRNA was more intricate than for 'simple' invertebrates. The key questions (both in terms of molecular mechanism and in terms of potential roles of RNA-triggered gene silencing as an immune process) revolved around a need to understand the structure of the molecular assembly responsible for recognition of the target message by the effector RNA. Like antibodyantigen complexes in classic immunity, the identification of a 'fundamental unit of recognition' seemed a key step in elucidating RNAi-based immunity in cells.

Some of this work could be done using $C$. elegans, and I will describe this in a bit of additional detail. Keep in mind (and I will describe at the end of this section) that much of the ongoing work was at this point being pursued in parallel in different systems by a plethora of research groups each with their own angle on a specific model organism and interference assay. RNAi is a three-strand process involving a sense strand and an antisense strand in the trigger and a target transcript in the cell. We could manipulate the trigger strands extensively in an attempt to determine exactly what was required for the induction of specific interference. This analysis gave several specific results. ${ }^{83}$ First, we found a different set of chemical requirements for the sense and the antisense strands in inducing interference. Second, there was a rather stringent requirement for sequence matching between the two trigger strands and with the target strand. Third, although there was a decrease in effectiveness as we used shorter and shorter triggers, we could obtain a response in $C$. elegans with triggers whose length was in the 20s of nucleotides. Combined with complementary structure-function experiments carried out at a similar time in other systems, ${ }^{84}$ these data evidenced a very concerted chemical precision of effector RNA recognition and action in the (at that point still very unknown) black box.

A second area in which $C$. elegans could readily contribute to the understanding of RNA-triggered silencing revolves around a genetic screen. The screen, originally executed by Hiroaki Tabara and Craig Mello, ${ }^{85}$ involved an important modification of Lisa Timmons' feeding experiment. Hiroaki 
engineered $E$. coli to produce a specific dsRNA, but in this case the dsRNA was targeted toward an essential gene in C. elegans (a gene called pos-1 that Hiroaki had characterized during his graduate work with Yuji Kohara ${ }^{86}$ ). Without the activity of this gene, worm populations could not survive, so that the engineered bacteria are an exceedingly poor food source for $C$. elegans. Selecting the extremely rare animals that can grow on that food source was then possible and was facilitated by working with populations that had been chemically treated several generations earlier to produce mutations. Among the animals that grew on this food source was a subset that lacked the responses to all the kinds of foreign dsRNA that we had used for interference. For at least two genes, Hiroaki found that a complete loss-of-function resulted in a worm that looked normal (or nearly normal) in the laboratory, but which was unable to respond to our dsRNA challenges. The existence of these mutations provided further (and very compelling) evidence that RNAi was a concerted process. If the ability of dsRNA to silence genes had been a simple reflection, for instance, of the physical chemistry of dsRNA, then we would have been unlikely to find mutations that abrogated this activity. That $C$. elegans could survive without the process and grow normally (at least in the artificially pristine conditions of an isolated Petri plate) was a demonstration that the organism relied on a dedicated mechanism to facilitate dsRNA-triggered silencing. Through considerable effort, mostly from Hiroaki and Craig, it was possible in a relatively short time to identify the genes that had been mutated in the resistant strains. The identities of the corresponding genes were both illuminating and frustrating.

rde-4 encoded a protein with a structure clearly suggestive of an ability to bind to dsRNA; ${ }^{87}$ although certainly reassuring, this identity by itself (and the expected ability of the protein to bind to dsRNA nonspecifically ${ }^{88}$ ) was not sufficient to illuminate the underlying mechanism.

rde-1 encoded a protein from a large family (now called the 'Argonaute' family) for which there was at the time only a trace of biochemical data. Proteins from related families had been shown to play key developmental roles. ${ }^{89-91}$ There was some indication of an RNA interaction, ${ }^{92}$ but there was little biochemical information beyond this. As it became clear that other genetic model organisms shared a dsRNA response mechanism, it likewise became clear (from genetics in plants, fungi, and flies ${ }^{93-95}$ ) that at least a subset, like $C$. elegans, could survive without this mechanism. The ability of diverse organisms to encode proteins of similar character to those involved in $C$. elegans gene silencing, and the eventual identification of homologous genes as functionally required for RNAi in distinct model systems ${ }^{95-97}$ supported the argument that we were all looking at a similar and conserved biological process. Beyond the standard 'model' organisms, the existence of homologous coding regions in mammals supported the argument that mammals might indeed also have similar responses if it were possible at some point to tease away the nonspecific response.

Despite these hopeful suggestions, the RNA structurefunction and genetic analysis had not put us in a position either to propose a unifying mechanism for RNAi or to design experiments to test for the efficacy of the system in mammals. Even in hindsight, going forward in either direction would have been complicated; in particular, the shortest RNAs that we had initially tested for interference in $C$. elegans ${ }^{83}$ were too long to have fit into the what we now know as the RISC complex (see below), and were not of the proper structure to provide side-effect-free gene silencing responses in mammalian cells.

Getting into the black box required a series of keen biochemical observations. I would not go into these observations in too much detail here, as the small RNAs that mediate exogenous and endogenous genetic control in diverse biological systems are certainly worthy of their own narrative. Still a summary of the small interfering RNA (siRNA) story serves to provide some context for how we now think about RNAi.

The first indication that a small RNA population might be key to the RNAi process came from experiments in plant systems that were carried out by Andrew Hamilton and David Baulcombe. ${ }^{98}$ Studying plants undergoing experimental gene silencing, they found a population with a narrow size range of 21-25 whose presence was closely associated with the silencing. Critical to this analysis was the decision to look for RNAs in a small size range and the rather impressive chemical trick of actually detecting these RNAs.

With small RNAs identified as potential additional characters in the story, biochemical research gained considerable momentum. To know anything about what was happening in the black box required an ability to study the reaction not within the complex environment of living cells, but in some type of isolated system. Two groups initially took up this challenge: one at MIT (Phil Zamore, Tom Tuschl, Ruth Lehman, David Bartel, and Phil Sharp) and one at Cold Spring Harbor (Scott Hammond, Emily Bernstein, David Beach, and Greg Hannon). Each succeeded independently (using very different approaches) in recapitulating the RNAi reaction in soluble extracts of Drosophila cells. ${ }^{99,100}$ As the analysis of the biochemical reaction proceeded from these groups and others, it became clear that the small RNAs that Hamilton and Baulcombe had observed in plants were indeed central to the interference reaction. The reaction was, at least conceptually, divided into three phases; the cleavage of a long dsRNA trigger into shorter dsRNA segments, the loading of chosen single-stranded products of this cleavage into a tight ribonucleoprotein complex, and the scanning of potential target RNAs in the cell by this complex..$^{99-102}$ The Hannon lab, perhaps while watching late-night television, coined catchy (and now standard) names for the two enzyme complexes central to the reaction: Dicer (which cleaves the dsRNA into short segments) and Slicer (which assembles around a single strand of processed effector RNA and goes on to cleave target messages (somewhat equivalent to the term RISC)).

The pathway that resulted from the confluence of biochemical and genetic analysis is shown graphically in Figure 6. The reaction initiates with cleavage of the large dsRNA fragment into small double-stranded fragments. Selected strands of single-stranded RNA then get incorporated into the 'slicer' complex, which then searches around the cell looking for target RNAs in a manner that is not yet understood. When those target RNAs are found, they are cleaved by an enzyme activity, which is intrinsic in the RISC, leading eventually to target degradation. Although this mechanism certainly didn't 


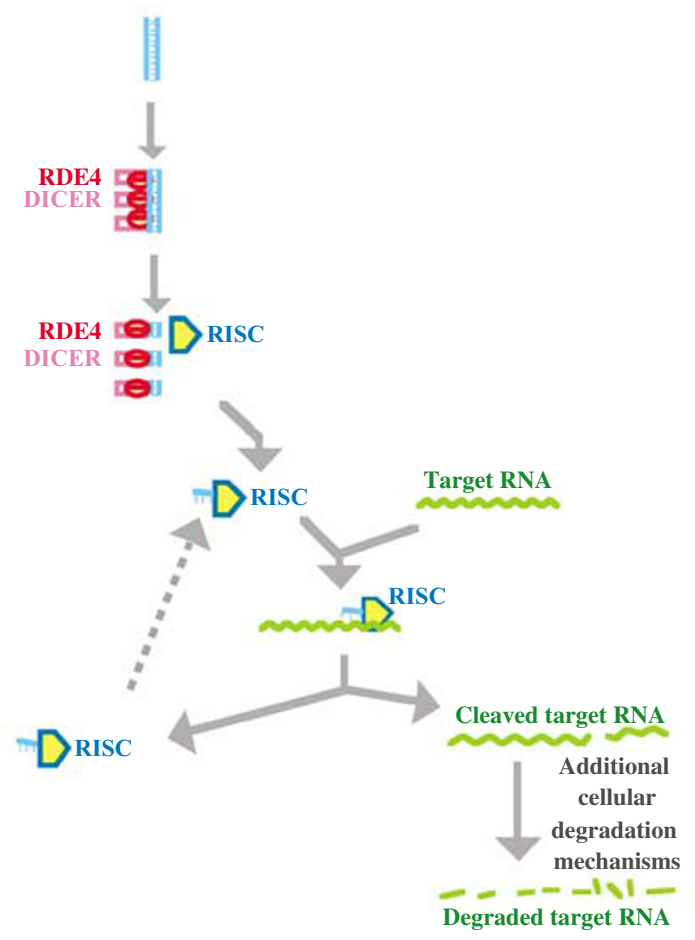

Figure 6 A basic model for the conserved central core mechanism in RNAi. Based on biochemical and genetic experiments as described in the text; dsRNA enters the cell, is set upon by a complex of a dsRNA-binding protein (RDE4 for C. elegans) and a dsRNA-specific nuclease (Dicer). Following dicing of the dsRNA into short double-stranded segments, individual small RNAs are loaded into a second protein complex including a protein member of the Argonaute family (to assemble an RNA-Induced-Silencing Complex, also called a 'RISC' complex). These can then survey the existing RNA population in the cell for matched targets, which are then subject to degradation

explain all of the phenomenology, it has proven remarkably general as a working model on which to base further study of RNAi.

Among the consequences of this model were some predictions of how to achieve specific RNAi in human cells. A key step in this was the detailed chemical description by Elbashir, Lendeckel, and Tuschl of the first small RNA intermediate in the silencing process. ${ }^{103}$ This mostly doublestranded small RNA population formed by Dicer had a characteristic set of termini with two slightly overhanging bases on each strand and the negatively charged phosphate group on the nonoverhanging end. Recall that long dsRNA induced a nonspecific effect, which prevented us from looking for any specific effects. Determination of the intermediate structure sparked an informed guess that RNAs of this structure, known from earlier studies to be too short to induce a strong nonspecific response, ${ }^{104}$ might produce a much more specific response. This was indeed the case, with reports appearing first from Elbashir, Tuschl, and colleagues, ${ }^{105}$ and then in rapid succession from other groups including our colleagues Natasha Caplen and Richard Morgan at National Institutes of Health. ${ }^{106}$ The relatively straightforward nature of these assays led quickly to adoption of siRNA-mediated interference as a preferred method for certain analyses of gene function in mammals.

\section{RNA Interference as Immunity: Some Analogies and Questions}

The genetic and biochemical elucidation of RNAi also raised some interesting questions of analogy between the classic immune response (involving antibodies and lymphocytes) and RNAi. First will come the question of specificity. For the classic immune system, specificity is enforced by a series of interactions between recognition proteins (antibodies and T-cell receptors) and their potential partners (including foreign proteins and other molecules). The flexibility of the specific protein recognition repertoire thus serves as major basis for the classic immune response. For intracellular responses to foreign RNA, it appears that nucleic acid complementarity plays a similar role. Hybridization of short effector RNAs to a target message provides both rapid and specific recognition on which to base an immune response. The critical length of the duplex, in the 15-25 nt range, turns out from first principles to be optimal for achieving specific recognition without burdening the system by nonspecific hybridization that would be more common with longer effector molecules (a point made many years ago by Tom Cech, in giving an introductory lecture in $\sim 1991$ to a group of scientists who hoped to use antisense technology for therapeutic goals).

A second challenge for the RNAi pathway is how to ensure that no self-attack occurs that might harm the host cell; essentially, there is a need to be sure that none of the cell's own essential genes are targeted by the RNAi mechanism. A part of this assurance relies on the use of dsRNA as a trigger. Our cells do not normally use dsRNA to express our genes; they use single-stranded RNA. Of course there may be cases where dsRNA is part of modulating gene expression, but for the most part, cells can avoid it if they need to. The interesting part of this avoidance is that it is evolutionary in nature. We presume that once the RNAi mechanism is in place, cells would evolve very diligently to avoid producing dsRNA in amounts that would shut off important endogenous genes. Any deviation from this could decrease the fitness of the organism, so over evolutionary time we expect a very effective avoidance of self-detrimental RNAi. This long-term mechanism differs from classic immunity in that the classic immune response avoids self-inflicted damage by a surveillance mechanism that (when everything is working properly) removes self-directed recognition elements continuously during the life of an organism. The consequence of this difference is that for RNA-based immunity it may be easier in real time to 'trick' the system into targeting an endogenous component, something that could be an encouragement to the development of therapeutic strategies involving RNAi.

Breaking of the initial dsRNA trigger into small fragments reveals a third immune-related logic to the process. Certainly the dicing of the trigger serves to increase the number of independent molecules (and specificities) in the response, potentially providing a more effective trigger:target ratio for surveillance. In addition to this, the focus on short segments allows the system to respond to viruses that have mutated elsewhere in the genome but kept one or more essential 
sequences of greater than 20 bases. Finally, there is a benefit to breaking the infectivity of the effector molecules before disseminating them around the organism. I usually describe this by analogy to antiviral software: If you are worried about viruses infecting your computer, you will buy an antiviral software package that carries (i) a database of information about viruses (computer viruses in that case), (ii) a series of routines to establish which files are infected, and (iii) a series of remedies which either correct or delete the infected files. The virus database that is part of this package does not need to have complete sequences for each virus, and indeed it would be a mistake for the antiviral software company to distribute such a database, as some of the components from the database might end up initiating infections. By taking from each virus only a set of relatively short signature sequences, it becomes possible to distribute identifying information without distributing the potential for infectivity. Breaking the dsRNA into 21-25 nt segments may serve the same role in cellular responses to unwanted RNA.

Dissemination of immune effector information is another feature of both classical and RNA-based immune mechanisms. For classical immunity, this involves hitch-hiking with the blood circulation that permeates the body, as well as some very highly choreographed lymphocyte migration processes. For RNA-based immunity, the mechanisms of information dissemination are still being unveiled. Results demonstrating a concerted protein-based machinery that mediates dissemination of the RNAi response in $C$. elegans ${ }^{107}$ are certainly exciting; understanding this machinery will be of great interest in designing and planning applications of RNAi.

RNAi, like any cellular mechanism, requires use of energy and metabolic resources. Balancing those resources with the current needs of the organism, and focusing the resources available for this purpose on the most pressing dangers, are essential for the system to fulfill its worth. For classic immunity, there are mechanisms that manage the population of effector molecules involved in surveillance ( $\mathrm{T}$ - and B-cell repertoire), both by subtracting out specificities that are not engaging targets and by amplifying specificities that engage their targets. One expects, perhaps, to find similar overall management of specificities that guide the RNAi machinery. An enticing example of such management comes from the involvement of RNA-directed RNA polymerases in the silencing process for plants, worms, and some single-celled organisms (see Figure 7). First characterized in plant systems in the 1970 s, cellular enzymes that can copy RNA to RNA ${ }^{108}$ had little place in the central dogma of molecular biology (DNA makes RNA makes Protein). Considerable doubt regarding the source of such enzymes inhibited research until they were purified and shown to be encoded by the cellular genome (109-110 $^{-11}$ and subsequently shown to play key roles in RNAi in Neurospora, worms, and plants. ${ }^{111-115}$ One of the striking aspects of RdRP-based trigger amplification that has been described is that amplification only occurs when a target has been engaged. The consequences of this guidance mechanism ${ }^{116-122}$ are (i) that amplification of the effector signal is limited to cases in which there is a real target, and (ii) that the spectrum of RNA silencing triggers can spread outside of the original area to encompass a broader segment of a target that has been recognized as foreign/unwanted. The

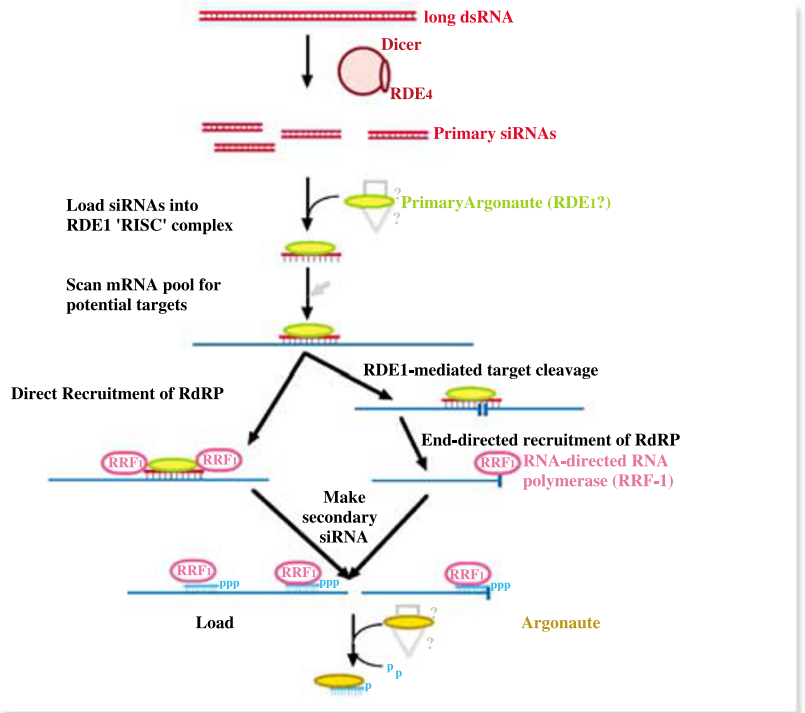

Figure 7 A model for amplified RNAi in C. elegans somatic tissue. Based on Discussion and references in the text, long dsRNA introduced into cells is initially attacked by a complex of a nuclease (Dicer) and a recognition component (RDE4) that 'dice' the long dsRNA into short fragments. Loading of these fragments into a second protein complex results in a silencing complex that can scan the message population of the cell for matching sequences. These are then subject to two different consequences: cleavage (which should inactivate the message) and/or synthesis of short complementary RNAs. ${ }^{116-122}$ The short complementary RNAs can join their own effector complexes (possibly including a different Argonaute family member, se ${ }^{143}$ ), resulting in a target-dependent amplification of the foreign dsRNA response. See text and references for further discussion of this proposed mechanism

RdRP-based amplification mechanism thus provides an example of honing the immune activity of the RNAi system to 'clear and present' dangers.

The immune system analogy to RNA-based surveillance brings up a final question of how the system can remember prior challenges to provide optimal immunity. For the majority of RNAi experiments done in $C$. elegans, the visible effect disappears after a generation or so. ${ }^{40}$ This is not always the case, however, and there are instances in which gene-specific effects of RNAi can last for numerous generations. ${ }^{123-124}$ Similar long-term effects have been studied in plant systems. ${ }^{125}$ Such effects would not be expected from the simple model in Figure 6. Instead, a current model (see Figure 8) is that the initial interaction between effector and target sequences might have a combination of short-term consequences (e.g. inhibition of translation and degradation of the target mRNA), medium term consequences (such as production of additional small RNA effectors complementary to the target) and long-term consequences (including changes in the physical conformation ${ }^{46,47}$ of the cellular DNA that encodes the target transcript). This variety of responses to a similar initial interaction event is in many ways analogous to the classic immune system, where an initial target recognition interaction can lead to a plethora of downstream consequences. In each case, the initial interaction complexes (RISC-mediated nucleic acid hybridization in the case of RNAi, antibody: antigen or T-Cell-Receptor:antigen in the case of the classic immune system) appear capable of 


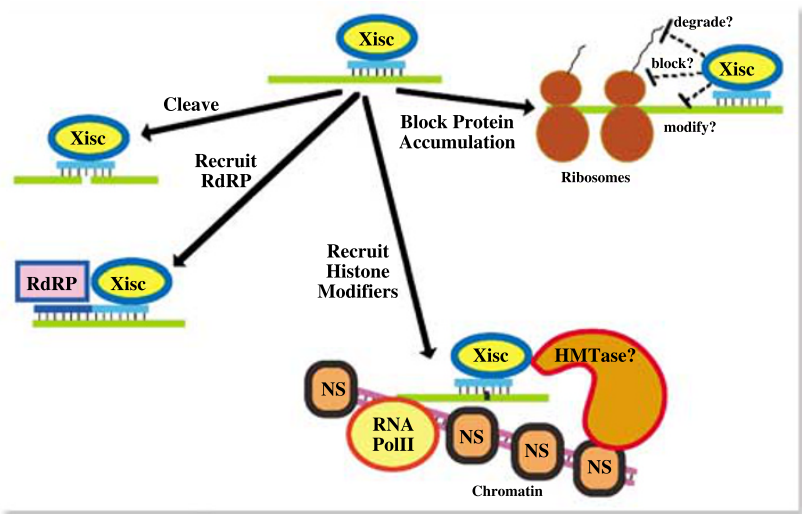

Figure 8 A model for multimodal gene silencing as a result of siRNA effector recognition of RNA transcripts. A generic Argonaute:siRNA:target ternary complex is shown at the top, giving rise in principal to several different complexes in which silencing factors have been recruited. Left, top: cleavage of target transcript by Argonaute-like component or a recruited ally. Left, middle: recruitment of an RNAdirected RNA polymerase that might synthesize complementary RNA either primed by the initial siRNA or (as appears to be the case in $C$. elegans) with de novo initiation. Bottom: a rough schematic diagram of tethered chromatin modification components acting on nearby nucleosomes and/or other DNA-associated factors (drawn here as a silencing HMT-ase = 'Histone methyltransferase,' [see ${ }^{145}$ ] although numerous other epigenetic modifying activities could function equivalently). Note that this process would likely occur on a nascent RNA transcript still associated physically with the DNA template. ${ }^{144}$ Right: recruitment of factor(s) that might block translation of the message ${ }^{48}$

recruiting a diversity of suppressive mechanisms based on the circumstances, with the duration of any given response (and subsequent memory) depending on a balance between longer and shorter term consequences.

\section{Going Forward: Puzzles and Challenges}

RNAi is an extremely active field of current investigation and will certainly remain so for some time. Many of the central questions relate to basic mechanisms; many others relate to potential applications. From the perspective of understanding RNAi as a potential immune-type surveillance mechanism, several questions currently occupy the forefront. One question concerns possible roles for RNAi as an antiviral response outside of the plant kingdom. Several recent studies in invertebrate animals (worms and flies) rather clearly show the capability of RNAi to function in surveillance against viruses (and other selfish information such as transposons) in simple animals. ${ }^{85,126,127,128}$ That the issue has not yet been resolved for higher animals (mammals), could conceivably reflect the complexity of teasing apart specific and nonspecific responses of mammals to dsRNA. Alternatively, it is certainly conceivable at this point that the virusprotective role of RNAi has been lost in mammals.

One exciting development over the last several years has been the appearance in the literature of detailed structures of components parts of the RNAi machinery. ${ }^{129,130}$ These structures have, both individually and in aggregate, led to an understanding of aspects of the mechanism which would have only been dreams during the early phases of the analysis of the system. With the emerging structural wisdom come a large number of thermodynamic and kinetic questions. For the less technically inclined reader, these challenge us to understand the contributions of energy and equilibrium to the natural system and to add the dimension of time to the static pictures such as those in Figures 6 and 7. Already it is clear that kinetic competition between different potential effectors at each stage of the RNAi mechanism is a key determinant of how the RNA-based surveillance system is used. ${ }^{131,132}$ Likewise, kinetic competition between the RNAi machinery and other protein: RNA interactions (RNA synthesis and processing machinery, RNA storage and turnover machinery, and the translation machinery) will undoubtedly determine the spectrum of RNAi events that can actually occur during the life of a cell. $^{133}$

At the same time, as detailed biochemical and structural studies are likely to illuminate the forefront of RNAi, there is still much to be learned from genetic analysis. The original screens of Tabara et al. ${ }^{85}$ found just two $C$. elegans genes with the idealized property that they eliminated almost all RNAi with little or no effect on the organism. Similarly, limited sets of comparable genes (although different individual components) were identified in the early genetic screens of plant and fungal systems. ${ }^{93,94}$ Vertebrate cells that lack the major Argonaute component involved in dsRNA-based surveillance are intriguingly alive (and capable of growth in a Petri dish) but incapable of forming a viable organism. ${ }^{134}$

Correspondingly, some mutants in other systems that may have superficially appeared specific to the dsRNA response also exhibit intriguing variations in growth and/or physiology even in the absence of known pathogenic challenges. ${ }^{135,136}$ In addition to these observations, several biological forces which were limiting the original genetic screens are now clear. In some cases, the failure to recover mutants affecting a given stage in the process reflected a degree of genomic redundancy, with several different gene products each sufficient (at least partially) to execute a single reaction step. ${ }^{85}$ Conversely, some RNAi components were not identified in the early screens due to their shared involvement in RNAi-related (but distinct) processes, which use similar molecular machineries and which are essential for organismal viability. In addition to the well-characterized micro RNA regulatory system, ${ }^{128,137}$ the portfolio of RNAi-related processes will almost certainly include surveillance and regulatory roles within cells which we have yet to understand. ${ }^{128}$ As the expanding toolkit for analyzing essential and redundant genes in genetic model systems is applied, we should be able to open more than a few doors toward illumination of both the natural roles of RNAi and of numerous yet-to-be-elucidated cellular regulatory and surveillance functions.

\section{RNA Interference as a Tool in Medicine?}

A question that has generated considerable excitement beyond the research lab is whether effector dsRNAs might be used as a direct intervention to treat human disease. Indirect applications of RNAi in medicine have certainly jumped forward: RNAi takes its place among many different tools to understand gene regulation, assign functions to individual genes, and facilitate the discovery of potential therapeutic targets in disease systems. 
Will direct administration of interfering RNA be a useful clinical tool? If a person has a virus infection, why not use dsRNA corresponding to that viral sequence as a drug to treat the person? If a person has a tumor, why not take a gene that is essential for that tumor and administer dsRNA corresponding to that gene to shut down growth of that tumor? If a person has a disease caused by an altered or out-of-control gene, why not try dsRNA corresponding to that gene as a potential therapeutic? There are many challenges and many conceivable benefits to this approach. There are scores of potential applications, all of which will require negotiating the thicket of delivery, safety, and efficacy in the complex circumstance of a genetically diverse target population and with the need to understand and anticipate host (and in some cases pathogen) responses to the specific dsRNA. Maybe the time frame in testing these approaches will be years, maybe tens of years, and maybe more. With all of the trepidation and caution that goes into such an enterprise, I still look forward to seeing research in this area progress as a future endeavor in both the public and the private sector.

I expect that there will be additional areas (beyond the gene discovery and therapeutic RNAi applications discussed above) in which understanding of RNA-triggered gene silencing will provide therapeutic opportunities and augment our capacity to mitigate disease. Any potent and specific biological process (even if it is generally beneficial to the organism) comes with consequences to the organism if abnormalities in specificity or regulation occur. Aberrations in genetic silencing (both positive and negative) are certainly a major component of many human diseases, including most prominently cancer. Intensive investigations of dysregulation in cancer and other diseases have turned up cases of defects in virtually every known cellular regulatory pathway. Regulation by small RNAs has rapidly joined this group, ${ }^{139,140}$ with currently available data likely accounting for only a small fraction of such effects. As the potential contributions of RNAtriggered genetic silencing processes to both disease and the human response to disease continue to be characterized, it is conceivable that there will be clear cases in which manipulation of the RNAi machinery itself, either in a global manner or in a small subset of cells or effector functions, will become an attractive therapeutic strategy. As such situations arise, the availability of therapeutic interventions to manipulate aspects of the RNAi machinery such as small molecule drugs, ${ }^{141}$ and biologically based modulatory strategies (e.g., using viral anti-silencing components) will certainly provide worthy leads for potential treatment.

\begin{abstract}
In randomized order: Lilly Lerner, Maria Esquela, Lynne Corboy, Yixian Zheng, Jenny Pang, Jim Manley, Robert Weinberg, Guy Rudin, Steven Siegel, Claire Craddock, John Hennessey, Andrew Godbey, Josh Glassman, Kevin O'Connell, Mark Lorell, Jim Kiessling, Benjamin Glass-Siegel, Ziva Reuveny, Gesine Dingkuhn, Vivian Hou, MarketBiology Students, Joe Robertson, Patrick Masson, Massachusetts Institute of Technology, Gabriel Chaen, Harold Smith, Caroline Mararah, Dina Goren,Sharon Long, Grace Fagalde, Rose Sherak, Mike Leong, Arend Sidow, Joan Miller, Metav Arusha, Peter Okkema, Elliott Meyrowitz, Aviva Richman, Robert Schleif, David Postman, Ursula Vogel, Ann Thompson, Barry Levine, Nathan Krantz-Fire, Michael Jantsch, David Remondini, Ed Hedgecock, Fred Tan, Mehrangiz Kamyab, Shira Lander Sondra Lazarowitz, Gilbert Chu, John Gage, Karen Rosenfeld, Allie Liu, Min Kim,Ann Crowden, Richard Meserve, Mike Cleary, Sonya Palmer, Art Barnes, Mike Krause, Ashley Chi, Ann Corsi, Nipam Patel, Parmjit Jat, Mark Eaton, Michael Shen, Ben Hwang, Lucy Sherill, Linda Breeden, David Finkel, Gregory Fisher, Irv Weissman, Judith Greenberg, Kerstin Arusha, Lisa Steiner, Peter Sarnow, David Baillie, Lisa Weymouth, Toshi Oyama, Ann Halvorsen, Richard Durbin, Naomi Richman, Helen Sherak, Helen Reichel, Claudia Lipschultz, Terence Murphy, Jade Li, Won Kyu Pak, Ruth Rose, Poornima Parameswaran, Susan Michaelis, Chip Ferguson, Ed Ziff, Donald Moerman, Miriam Goodman, Bill Tiefenwerth, Kathy Meyrowitz, Chris Halvorsen, Mary Montgomery, Paul Chernoff, Josianne Eid, David Housman, Ben Hole, Cliff
Tabin, Sarina Schwartz, The Fremont Chess Club, Betty Dyer, Garfield Moore, Julia Kay, Robin Kulakow, Kevin VanDoren, William Hurlbut, Charles Long, Daniel Blanchard, Sudha Mitra, Brittany Little, Peter Waterhouse, Casey Inman, Sara Eisenberg, Bill Fixen, Rachel Krantz, Mark Samuels, Maria Jasin, Geraldine Seydoux, Victor Ambros, Inder Verma, Chang Zhang Chen, Titia Sijen, Barbara Elspas, Jorge Mancillas, Elana Lubit, Steve Johnson, David Schwartz, Barbara Levine, Joyce Rosenfeld, Blake Hill, Hollenbeck Elementary School, Ruth Shinn, Phillip Sharp, Paul Englund, John Burke, Scott Oliver, Yvonn Pon, Peter Hahn, Amy Locks, Ben Stern,Marvin Sherak, Paul Kokulis, Clifford Locks, Robert Tjian, Siva Ophir, Beth Johnston, John Gearhart, HeeYoung Kim, Denise Montell, Tory Prestera, Susan WhiteHarrison, Adi Ophir, Phil Beachy, Sam Halvorsen, Julia Pak, Alan Klotz, Hugh Rienhoff, Robert Waterston, Stuart Kim, Barbara Postman, Mary Dasso, Gina Fisher, Maurice Fox, Sarah Katz, Anita Finkel, Morgan Park, Maxine Singer, Gerry Crabtree, Mitch Kostich, Rick Myers, Carol Alberts, Peter Jackson, Ira Dyer, Levana Ruthschild, Daniel Nathans, Cynthia Kenyon, The National Institute of Child Health and Development, Joe Heilig, Sylvia O'Neill, The Balzano Family, Gary Otto, Ellen Zucker, The Medical Research Council, Yvette Goren, Simon Xu, Nancy Paiva, Andy Golden, Nancy Craig, Philip Anderson, Ellie Krantz, Mary Beth Shinn, Donna Rae Machado, Nina Federoff, Ann Sharp, Genevieve Fire-Halvorsen, Eleanor Maine, John Etchemendy, Richard Henderson, Gary Ruvkun, Ichi Maruyama, Kamiko Cangelosi, Shou Wei Ding, Mel Goudy, Hank Greely, Randall Kaufman, Geeta Narlikar, Haifan Lin, Victor Corces, Matt Kowitt, Alyssa Zucker, Alan Wolffe, Arielle Goren, Lynne Spencer, Joey Finkel, Christine Norman, Joe Adler, Sam Fire, Nichol Thompson, Kathy Sherak-Chen, Kam Ophir, Richard Calendar, Judith Geller, Ken Kemphues, Mark Benvenuto, Judith Kimble, Nancy Hopkins, Susan Strome, Michael McCaffery, Kathy Berkner, Rich Breyer, Ann Brunet, Kirsten Crossgrove, Richard Jorgensen, Greg Wiederrecht, Ellen Cammon, Allan Shearn, 7_03 Students, Wendy Locks, Jim Darnell, Rebecca Raitzig, Kwok Han Lian,
William Pavao, Baltimore-Washington Worm Club, Karla Kirkegaard, Ihor Lemischka, Miriam Fire, Ron Millar, Laura Loveland, Linda Henry, Lewis Chodosh, Mr. Steffen, Harold Weintraub, Path_218 Students, William Pavao, Baltimore-Washington Worm Club, Karla Kirkegaard, Ihor Lemischka, Miriam Fire, Ron Millar, Laura Loveland, Linda Henry, Lewis Chodosh, Mr. Steffen, Harold Weintraub, Path_218 Students,
Joe Vokroy, Lois Edgar, Bill Reichel, Natasha Caplen, Ms. Escolar, the Fremont Math Club, Ms. Wilson, Nancy Blachman, Andy Hopkins, Jim McGhee, Hung Hsi Wu, Charles Yanofsky, Felix Khuner, De Anza Joe Vokroy, Lois Edgar, Bill Reichel, Natasha Caplen, Ms. Escolar, the Fremont Math Club, Ms. Wilson, Nancy Blachman, Andy Hopkins, Jim McGhee, Hung Hsi Wu, Charles Yanofsky, Felix Khuner, De Anza
College, Craig Mello, Steven Leong, Ken Lorell, Tim Schedl, Marcus Thompson, Robert Herman, Ilil Carmi, Heather McCullough, Gideon Eisenberg, Frederica Postman, Anne Villeneuve, Don Doering, Dan College, Craig Mello, Steven Leong, Ken Lorell, Tim Schedl, Marcus Thompson, Robert Herman, Ilil Carmi, Heather McCullough, Gideon Eisenberg, Frederica Postman, Anne Villeneuve, Don Doering, Dar
Donoghue, Margalit Krantz-Fire, Sarah Shaeffer, The Shapiro Family, Elias Speliotes, Peter Sklar, Ms. Beaufenkamp, Jim Kent, Nelson Blachman, Allan Spradling, Scott Hammond, Gail Shokat, David Baulcombe, Helen Hart, Jerry Fox, Menachem Ophir, Karen Lamarco, Michel Goedert, Ken Fisher, Zeke Gluzband, Molly Marcus, Don Riddle, Matt vanderRijn, The Helen Hay Whitney Foundation, Sim Esquela, Baulcombe, Helen Hart, Jerry Fox, Menachem Ophir, Karen Lamarco, Michel Goedert, Ken Fisher, Zeke Gluzband, Molly Marcus, Don Riddle, Matt vanderRijn, The Helen Hay Whitney Foundation, Sim Esquela The National Science Foundation, Chaen Chaen, Tamir Ophir, Elizabeth Lincoln, Gavi Swerling, Jay Maniar, Lisa Sklar, Cori Bargmann, Sarah Barker, Mark Edgley, David Botstein, Jonathan Khuner, James Duc,
Jim Lewis, Al Rosenfeld, Rachel Grossman, Doris Lorell, Richard Sutch, Jeff Shamma, Hannes Vogel, Bernie Elspas, Bruce Hoover, Jeff Yuan, Ky Sha, Suzy Halvorsen, Gloria Brienza, Chris Walsh, Forrest Foor, Sydney Brenner, Mike Finney, Georgia Rosenblatt, Marvin Rosenfeld, Shrage Ophir, Micah Glass-Siegel, Rainer Sachs, Mark Kay, Greg Robinson, Connie Clay, Andrea Swerling, Greg Hannon, Tom Leong, Femke Simmer, Shin Lin, Dan Riordan, Tom Lee, Samantha Glassman, Mark Bretscher, Doug Vollrath, Steve Galli, Louise Pape, Nadia Rosenfeld, Megan Jacoby, Florence Locks, Mary Lou Pardue, Jeff Levinsky, Femke Simmer, Shin Lin, Dan Riordan, Tom Lee, Samantha Glassman, Mark Bretscher, Doug Vollrath, Steve Galli, Louise Pape, Nadia Rosenfeld, Megan Jacoby, Florence Locks, Mary Lou Pardue, Jeff Levinsky,
The National Institute of General Medical Sciences, Ms. Benevides, Dan Stinchcomb, Steve Carr, David Baltimore, Aaron Mitchell, Frank Solomon, Aurora Kerscher, Saul Roseman, Arash Aryana, Timothy Bach, Roger Kornberg, Theresa Fritchle, Jamie Fleenor, Gladys Sherak, Sherrie Rakvin, Julie Baker, Joel Postman, Arlene Oyama, Fremont High School, Jim Priess, Tom McDonough, Beth Hare, Don Katz, Karen Beemon, Nelson Tandoc, Antoinette Glumac, Diane Leong, Nancy Maizels, Virginia Walbot, Phil Zamore, Mike Cherry, David Rosenfeld, Marc Shinn-Krantz, Hugh Tyson, Doug Fambrough, Michael
Wassenegger, David Shore, Robert Horvitz, Matthew Grossman, Jack Lorell, Izzy Goren, Gary Struhl, Roy Halvorsen, Colin Hampton, David Lipman, Lester Dubins, Carl Baker, Jimo Borjigin, Erika Matunis David Krantz, Bob Kingston, Ciel Berman, Tamara Doering, Martha Elspas, Teymour Boutros Ghalli, Jim Barsoum, Paul Miller, SuSun Slatky, Norma Fire, The University of California Santa Cruz, Shiming Chen, Gunther Stent, Steve Ellege, David Hirsch, Miriam Adler, Doug Koshland, Sherman Elspas, Ms. Fucile, Marcia Glass-Siegel, Alan Zahler, William Kelly, Connie Jewell, The University of California Berkeley, Jocelyn Shaw, Dennis Dixon, William Rossi, Peter Lawrence, Steve Kostas, Al Scott, The Rita Allen Foundation, Rick Irvin, Silas Xu, David Nelson, Kathy Wilson, Peter Kulakow, Tom Tullius, Jenny Hsieh, Uttam Rajbhandary, Susan Dymecki, Chelsea Glassman, Iva Greenwald, Judith Yanowitz, William Wood, Steve Wasserman, Ann Rose, Clarissa Cangelosi, Ann-Marie Macdonald, Weng Onn Lui, Tim Hunt, Michael Sklar, Genetics 235 Students, Mark Palm, Spice Kleinman, Mia Horowitz, Ellen Henderson, Michael Shokat, Eric Kostlan, Ann Marie Murphy, Jeff Axelrod, John Pringle, Alejandro Sanchez, Ulla Hansen,
Deborah Robbins, Lisa Timmons, William Sherak, Lincoln Stein, Casonya Johnson, Nancy Locks, Bill Courchesne, Greg Barsh, Ronald Plasterk, David Meyrowitz, Orit Ophir, Trelligans Inc, Chris Phillips, Becky Deborah Robbins, Lisa Timmons, William Sherak, Lincoln Stein, Casonya Johnson, Nancy Locks, Bill Courchesne, Greg Barsh, Ronald Plasterk, David Meyrowitz, Orit Ophir, Trelligans Inc, Chris Phillips, Becky Hohman, Stan Finkel, Steven Tschantz, Scott Rosenfeld, Robert Brown, Phil Cormier, Hilla Keren, Rachel Meyrowitz, Laurie Kovens, Nina Sherak, Brian Horblit, Howard Sklar, Ben Sher, Susan Parrish, Peter
Sorger, Philip Fire, Miles Greiner, Boris Magasanik, Frank Laski, John White, Jake Raitzig, Chen Ming Fan, Carrie Athans, Paul Shimmel, Daniel Shinn-Krantz, Tom Changnan, Sam Dadras, Susan Kern, Kyung Sorger, Philip Fire, Miles Greiner, Boris Magasanik, Frank Laski, John White, Jake Raitzig, Chen Ming Fan, Carrie Athans, Paul Shimmel, Daniel Shinn-Krantz, Tom Changnan, Sam Dadras, Susan Kern, Kyung Lee, Kiyoshi Nagai, Verena Jantsch, Jonathan Adler, Nigel Crawford, Sam Ward, HsuTze Lee, Bruce Vogel, Robert Ely, David Miller, Joe Gall, Jonathan Gent, Jonathan Hodgkin, Susan Blachman, Miriam Fox, Margarita Siafaca, Michael Senturia, Steve L'Hernault, Marian Barber, Michael Adler, Diane Shakes, Naudia Lauder, Saul Glass-Siegel, Donald Brown, Stanford University, Marnie Halpern, Pat Englar, Judith
Swan, Malcolm Gefter, Ari Krantz, Maitreya Levanchild, Barbara Messenger, The National Institutes of Health, Michael Brent, Lihsia Chen, Elizabeth Glassman, John Sulston, Paul Sternberg, Susanna Lewis, Bingwei Lu, Man Wah Tan, Gary Tanegawa, Ann Blachman, Hiroaki Kagawa, Tina Trapane, Cecilia Mello, Nathan Landau, Eric Fyrberg, Tom Loveland, Dan Richman, Barbara Sollner-Webb, Dennis Balinger, David Friedheim, Bill Kupiec, Zhou Wang, Earl Potts, Narry Kim, Mike Fuller, Stella Kerscher, Carol Berkower, Carolyn Norris, Mary Waye, Russell Rarity, Pnina Ophir, Guy Benian, Lucy Sherak, Chalermporn Ongvarrasopone, Janet Fire, Rich Mulligan, Robert Rosenfeld, Michael Klass, Richard Morgan, Iris Martinez, The Carnegie Institution of Washington, Rachel Hertzman, Witold Filipowicz, Andy Hoyt, Janet Williams, Doug Melton, Kaja Arusha, Joel Schildbach, Johns Hopkins University, Calvin Moore, Mortimer Locks, Yossi Gruenbaum, Connie Cepko, 020_731 Students, Irving Zucker, RuChih Huang, Sam Driver,
Ian Purse, JooHong Ahnn, Maurice Bessman, Gene Brown, Lenny Brand, The Medical Research Council Laboratory of Molecular Biology, Karen Perry, Oliver Kerscher, Brian Harfe, Glenese Johnson, Rose Stern, Rose Kass, Sam Katz, Chaya Krishna, SiQun Xu, Ruth Starczyk, Elsabetta Ullu, Donna Albertson, Math_51C Students, Harvey Lodish, Stan Balazar, Tom Fulton, Phil Pizzo, 020_348 Students, Rosa Alcazar, Sarah Hammontree, Karen Chapman, Adam Rosenblatt, Louisa Ho, Richard Pagano, Marianne Bienz, Nicholas Hammontree, The American Cancer Society, Tom Blumenthal, Anna Esquela, Constance Sherak, Hugh Pelham, Monty Lerner, Karin Kopciak, Corwin Shokat, Paula Grabowski, Michael Wilcox, Mohammed Islam, Allen Strause, Nathan Sato, Rebecca Krantz, Magda Konarska, Sally Robinson-Seaver, Marty Chalfie, Bino Palmer, David Landsman, Steve Hardy, Michael Raitzig, Seth Alberts, Iliana Sherak, Jonathan Zucker, Mary Esteve, Richard Craddock, Eric Haag, Lori Steffy, Mango Junior High School, Crystal Myers, Donald Sherak, Mei Hsu, Elizabeth Lee, Tabitha Doniach, William Whitson, Steven Locks, Micro 233 Students, Stan Cohen, Richard Padgett, Larry Lasky, Anthony Hyman, Robert Sherak, Tom Tuschl, Charles Vinson, Bruce Reynolds, Doug Harrison, Lia Gracey, Patty Winningham, Mike Sepanski, Pat Cammon, Mike Cangelosi, Richard Swerling, Marina Ratner, Kelly Liu, Amy Alper, David Eisenmann, Jo Lipsick, Monroe Postman, Phil Newmark, Steve McKnight, Richard Field, Ms. Mayfield, Allan Kensky, Bernard Sherak, William Matlack, Trina Shroer, Kyle Cunningham, Steve Winans, Eric Barklis, more...
\end{abstract}

Figure 9 A few of the people and groups that the author would like to acknowledge for their help, support and encouragement. The list is in computationally randomized order with a few omissions (apologies) and misspellings (apologies) 


\section{Science does not Grow on Trees, Even in Santa Clara County}

I want to finish with a few thanks. I have been fortunate to be associated with a family, a group of friends, a set of coworkers, and a number of institutions for which scientific inquiry and humanity have been equally highly valued. This has made it a joy to do science.

Since this article focuses most directly on experiments from the 1990s on the structural trigger for RNAi, I want to first specifically acknowledge the members of my lab and some of our collaborators that were directly involved in this work. The crew in my lab that were involved most directly in this particular effort were SiQun Xu, Mary Montgomery, Steve Kostas, Lisa Timmons, Susan White-Harrison, Jamie Fleenor, and Susan Parrish. Collaborations with Craig Mello and his group, particularly Sam Driver and Hiroaki Tabara likewise drove the effort in wonderful ways, as did collaborations with Natasha Caplen and Rick Morgan at National Institutes of Health, Farhad Imani at Johns Hopkins, and Titia Sijen, Femke Simmer, Karen Thijsen, and Ronald Plasterk at Utrecht. I hope you realize that even this rather substantial scientific consortium was just a piece of a very large puzzle that involves also many other scientists and groups around the world.

Two institutions deserve particular attribution for any contributions from myself and my lab. The Carnegie Institution of Washington's Department of Embryology is where we did our work on the structural characterization of the trigger, and the National Institutes of Health (in addition to supporting all of our colleagues and collaborators) funded all of the work that has gone on in my lab on this question.

For anybody to make their way in the world, there need to be inputs and contributions... and a lot of influences. When I sat down to put a few names down of people that at one point or another have had a positive influence, Figure 9 emerged. I apologize in advance for any inadvertent omissions (and numerous spelling errors)... you know who you are.

1. Watson J, Crick F. Molecular structure of nucleic acids; a structure for deoxyribose nucleic acid. Nature 1953; 171: 737-738.

2. Rich A, Davies D. A new two-stranded helical structure: polyadenylic acid and polyuridylic acid. J Am Chem Soc 1956; 78: 3548.

3. Volkin E, Astrachan L. Phosphorus incorporation in Escherichia coli ribo-nucleic acid after infection with bacteriophage T2. Virology 1956; 2: 149-161.

4. Hall B, Spiegelman S. Sequence complementarity of T2-DNA and T2- specific RNA. Proc Natl Acad Sci USA 1961; 47: 137-163.

5. Spencer M, Fuller W, Wilkins M, Brown G. Determination of the helical configuration of ribonucleic acid molecules by X-ray diffraction study of crystalline amino-acid-transfer ribonucleic acid. Nature 1962; 194: 1014-1020.

6. Rosenberg J, Seeman N, Kim J, Suddath F, Nicholas H, Rich A. Double helix at atomic resolution. Nature 1973; 243: 150-154.

7. Montagnier L, Sanders F. Replicative form of encephalomyocarditis virus Ribonucleic Acid. Nature 1963; 199: 664-667.

8. Weissmann C, Borst P, Burdon R, Billeter M, Ochoa S. Replication of viral RNA, III. Doublestranded replicative form of MSW phage RNA. Proc Natl Acad Sci USA 1964; 51: 682-690.

9. Baltimore D, Becker Y, Darnell J. Virus-specific double-stranded RNA in poliovirusinfected cells. Science 1964; 143: 1034-1036.

10. Hoskins M. A protective action of neurotropic against viscerotropic yellow fever virus in Macacus rhesus. Am J Trop Med Hyg 1935; 15: 675-680.

11. Findlay $G$, MacCallum $F$. An interference phenomenon in relation to yellow fever and other viruses. J Path Bact 1937; 44: 405-424.

12. Isaacs F, Lindenmann J. Virus Interference. I. The Interferon. Proc Royal Soc B 1957; 147: 268-273.

13. Shope R. An antiviral substance from Penicillium funiculosum. J Exp Med 1953; 97: 601-650.

14. Lampson G, Tytell A, Field A, Nemes M, Hilleman M. Inducers of interferon and host resistance. I. Double-stranded RNA from extracts of Penicillium funiculosum. Proc Nat Acad Sci USA 1967; 58: 782-789.
15. Field A, Tytell A, Lampson G, Hilleman M. Inducers of interferon and host resistance. II. Multistranded synthetic polynucleotide complexes. Proc Natl Acad Sci USA 1967; 58 : 1004-1010.

16. Tytell A, Lampson G, Field A, Hilleman M. Inducers of interferon and host resistance. 3. Double-stranded RNA from reovirus type 3 virions [reo 3- RNA]. Proc Natl Acad Sci USA 1967; 58: 1719-1722.

17. Field A, Lampson G, Tytell A, Nemes M, Hilleman M. Inducers of interferon and host resistance, IV. Double-stranded replicative form RNA [MS2-Ff- RNA] from E. coli infected with MS2 coliphage. Proc Natl Acad Sci USA 1967; 58: 2102-2108.

18. Wingard S. Hosts and symptoms of ringspot, a virus disease of plants. J Agric Res 1928; 37: 127-153.

19. Price W. Virus concentration in relation to acquired immunity from tobacco ringspot. Phytopathology 1936; 26: 503-529.

20. Brenner S. Nature's gift to science [Nobel lecture]. Chembiochem 2003; 4: 683-687.

21. Kimble J, Hodgkin J, Smith T, Smith J. Suppression of an amber mutation by microinjection of suppressor tRNA in C. elegans. Nature 1982; 299: 456-458.

22. Stinchcomb D, Shaw J, Carr S, Hirsh D. Extrachromosomal DNA transformation of Caenorhabditis elegans. Mol Cell Biol 1985; 5: 3484-3496.

23. Fire A. Integrative transformation of Caenorhabditis elegans. EMBO J 1986; 5: 2673-2680.

24. Mello C, Kramer J, Stinchcomb D, Ambros V. Efficient gene transfer in C. elegans: extrachromosomal maintenance and integration of transforming sequences. EMBO $J$ 1991; 10: 3959-3970.

25. Mello C, Fire A. DNA transformation. Methods Cell Biol 1995; 48: 451-482.

26. Brenner S. The genetics of Caenorhabditis elegans. Genetics 1974; 77: 71-94.

27. Moerman D, Baillie D. Genetic organization in Caenorhabditis elegans: fine-structure analysis of the unc-22 gene. Genetics 1979; 91: 95-103.

28. Moerman D, Benian G, Waterston R. Molecular cloning of the muscle gene unc-22 in Caenorhabditis elegans by Tc1 transposon tagging. Proc Natl Acad Sci USA 1986; 83. 2579-2583.

29. Fire A, Moerman D. Transgenic Twitchers. Worm Breed Gaz 1986; 9[2]: 13-15.

30. Stephenson M, Zamecnik P. Inhibition of Rous sarcoma viral RNA translation by a specific oligodeoxyribonucleotide. Proc Natl Acad Sci USA 1978; 75: 285-288.

31. Izant J, Weintraub H. Inhibition of thymidine kinase gene expression by anti-sense RNA: a molecular approach to genetic analysis. Cell 1984; 36: 1007-1015.

32. Fire A, Harrison S. Sense and antisense disruption of muscle genes. Worm Breed Gaz 1988; 10: 89-90.

33. Fire A, Albertson D, Harrison S, Moerman D. Production of antisense RNA leads to effective and specific inhibition of gene expression in C. elegans muscle. Development 1991; 113: 503-514

34. Guo S, Kemphues K. par-1, a gene required for establishing polarity in $C$. elegans embryos, encodes a putative Ser/Thr kinase that is asymmetrically distributed. Cell 1995; 81: 611-620.

35. Rocheleau C, Downs W, Lin R, Wittmann C, Bei Y, Cha Y et al. Wnt signaling and an APC-related gene specify endoderm in early C. elegans embryos. Cell 1997; 90: 707-716.

36. Kuwabara $P$. Interspecies comparison reveals evolution of control regions in the nematode sex-determining gene tra-2. Genetics 1996; 144: 597-607.

37. Seydoux G, Fire A. Soma-germline asymmetry in the distributions of embryonic RNAs in Caenorhabditis elegans. Development 1994; 120: 2823-2834.

38. Soukup G, Breaker R. Relationship between internucleotide linkage geometry and the stability of RNA. RNA 1999; 5: 1308-1325.

39. Mellits K, Pe'ery T, Manche L, Robertson H, Mathews M. Removal of double-stranded contaminants from RNA transcripts: synthesis of adenovirus VA RNAi from a T7 vector. Nucleic Acids Res 1990; 18: 5401-5406.

40. Fire A, Xu S, Montgomery M, Kostas S, Driver S, Mello C. Potent and specific genetic interference by double-stranded RNA in Caenorhabditis elegans. Nature 1998; 391 806-811.

41. Montgomery M, Xu S, Fire A. RNA as a target of double-stranded RNA-mediated genetic interference in Caenorhabditis elegans. Proc Natl Acad Sci USA 1998; 95: 15502-15507.

42. Tomizawa J, Itoh T, Selzer G, Som T. Inhibition of ColE1 RNA primer formation by a plasmid-specified small RNA. Proc Natl Acad Sci USA 1981; 78: 1421-1425.

43. Chalker D, Yao M. Nongenic, bidirectional transcription precedes and may promote developmental DNA deletion in Tetrahymena thermophila. Genes Dev2001; 15: 1287-1298.

44. Mochizuki K, Fine N, Fujisawa T, Gorovsky M. Analysis of a piwi-related gene implicates small RNAs in genome rearrangement in tetrahymena. Cell 2002; 110: 689-699.

45. Yang V, Lerner M, Steitz J, Flint S. A small nuclear ribonucleoprotein is required for splicing of adenoviral early RNA sequences. Proc Natl Acad Sci USA 1981; 78: 1371-1375.

46. Wassenegger M, Heimes S, Riedel L, Sanger H. RNA-directed de novo methylation of genomic sequences in plants. Cell 1994; 76: 567-576.

47. Ingelbrecht I, Van Houdt $\mathrm{H}$, Van Montagu M, Depicker A. Posttranscriptional silencing of reporter transgenes in tobacco correlates with DNA methylation. Proc Natl Acad Sci USA 1994; 91: 10502-10506.

48. Olsen $\mathrm{P}$, Ambros $\mathrm{V}$. The lin-4 regulatory RNA controls developmental timing in Caenorhabditis elegans by blocking LIN-14 protein synthesis after the initiation of translation. Dev Biol 1999; 216: 671-680.

49. Gall J, Pardue M. Formation and detection of RNA-DNA hybrid molecules in cytological preparations. Proc Natl Acad Sci USA 1969; 63: 378-383.

50. Chalfie M, Tu Y, Euskirchen G, Ward W, Prasher D. Green fluorescent protein as a marker for gene expression. Science 1994; 263: 802-805. 
51. Heim R, Cubitt A, Tsien R. Improved green fluorescence. Nature 1995; 373: 663-664.

52. Kelly W, Xu S, Montgomery M, Fire A. Distinct requirements for somatic and germline expression of a generally expressed Caernorhabditis elegans gene. Genetics 1997; 146 227-238.

53. Timmons L, Fire A. Specific interference by ingested dsRNA. Nature 1998; 395: 854

54. Tabara $\mathrm{H}$, Grishok A, Mello $\mathrm{C}$. RNAi in $C$. elegans: soaking in the genome sequence. Science 1998; 282: 430-431

55. Kennerdell J, Carthew R. Use of dsRNA-mediated genetic interference to demonstrate that frizzled and frizzled 2 act in the wingless pathway. Cell 1998; 95: 1017-1026.

56. Misquitta L, Paterson B. Targeted disruption of gene function in Drosophila by RNA interference [RNA-i]: a role for nautilus in embryonic somatic muscle formation. Proc Natl Acad Sci USA 1999: 96: 1451-1456.

57. Ngo H, Tschudi C, Gull K, Ullu E. Double-stranded RNA induces mRNA degradation in Trypanosoma brucei. Proc Natl Acad Sci USA 1998; 95: 14687-14692.

58. Waterhouse $P$, Graham $M$, Wang $M$. Virus resistance and gene silencing in plants can be induced by simultaneous expression of sense and antisense RNA. Proc Natl Acad Sci USA 1998; 95: 13959-13964.

59. Ui-Tei K, Zenno S, Miyata Y, Saigo K. Sensitive assay of RNA interference in Drosophila and Chinese hamster cultured cells using firefly luciferase gene as target. FEBS Lett 2000; 479: 79-82.

60. Wianny F, Zernicka-Goetz M. Specific interference with gene function by double-stranded RNA in early mouse development. Nat Cell Biol 2000; 2: 70-75.

61. Svoboda P, Stein $P$, Hayashi $H$, Schultz R. Selective reduction of dormant maternal mRNAs in mouse oocytes by RNA interference. Development 2000; 127: 4147-4156.

62. Caplen N, Fleenor J, Fire A, Morgan R. dsRNA-mediated gene silencing in cultured Drosophila cells: a tissue culture model for the analysis of RNA interference. Gene 2000; 252: 95-105.

63. Selker E, Cambareri E, Jensen B, Haack K. Rearrangement of duplicated DNA in specialized cells of Neurospora. Cell 1987; 51: 741-752.

64. Goyon C, Faugeron G. Targeted transformation of Ascobolus immersus and de novo methylation of the resulting duplicated DNA sequences. Mol Cell Biol 1989; 9: 2818-2827.

65. Napoli C, Lemieux C, Jorgensen R. Introduction of a chimeric chalcone synthase gene into petunia results in reversible co-suppression of homologous genes in trans. Plant Cell 1990; 2: 279-289.

66. van der Krol A, Mur L, Beld M, Mol J, Stuitje A. Flavonoid genes in petunia: addition of a limited number of gene copies may lead to a suppression of gene expression. Plant Cell 1990; 2: 291-299.

67. Romano N, Macino G. Quelling: transient inactivation of gene expression in Neurospora crassa by transformation with homologous sequences. Mol Microbiol 1992; 6: 3343-3353.

68. Cameron F, Jennings P. Inhibition of gene expression by a short sense fragment. Nucleic Acids Res 1991; 19: 469-475.

69. Cambareri E, Jensen B, Schabtach E, Selker E. Repeat-induced G-C to A-T mutations in Neurospora. Science 1989; 244: 1571-1575.

70. deCarvalho F, Gheysen G, Kushir S, Montagu M, Inzé D, Castensana C. Suppression of $\beta$-1,3-glucanase transgene expression in homozygous plants. EMBO J 1992; 11: 2595-2602.

71. Cogoni C, Irelan J, Schumacher M, Schmidhauser T, Selker E, Macino G. Transgene silencing of the al- 1 gene in vegetative cells of Neurospora is mediated by a cytoplasmic effector and does not depend on DNA-DNA interactions or DNA methylation. EMBO J 1996; 15: 3153-3163.

72. Palauqui J, Elmayan T, Pollien J, Vaucheret $H$. Systemic acquired silencing: transgenespecific post-transcriptional silencing is transmitted by grafting from silenced stocks to non-silenced scions. EMBO J 1997; 16: 4738-4745.

73. Voinnet O, Baulcombe D. Systemic signalling in gene silencing. Nature 1997; 389: 553

74. Abel P, Nelson R, De B, Hoffmann N, Rogers S, Fraley R et al. Delay of disease development in transgenic plants that express the tobacco mosaic virus coat protein gene. Science 1986; 232: 738-743

75. Lindbo J, Silva-Rosales L, Proebsting W, Dougherty W. Induction of a highly specific antiviral state in transgenic plants: implications for regulation of gene expression and virus resistance. Plant Cell 1993; 5: 1749-1759.

76. Kumagai M, Donson J, della-Cioppa G, Harvey D, Hanley K, Grill L. Cytoplasmic inhibition of carotenoid biosynthesis with virus-derived RNA. Proc Natl Acad Sci USA 1995; 92 1679-1683.

77. Anandalakshmi R, Pruss G, Ge X, Marathe R, Mallory A, Smith T et al. A viral suppressor of gene silencing in plants. Proc Natl Acad Sci USA 1998; 95: 13079-13084.

78. Kasschau K, Carrington J. A counterdefensive strategy of plant viruses: suppression of posttranscriptional gene silencing. Cell 1998; 95: 461-470.

79. Beclin C, Berthome R, Palauqui J, Tepfer M, Vaucheret $\mathrm{H}$. Infection of tobacco or Arabidopsis plants by CMV counteracts systemic post-transcriptional silencing of nonviral [trans]genes. Virology 1998; 252: 313-317.

80. Brigneti G, Voinnet O, Li W, Ji L, Ding S, Baulcombe D. Viral pathogenicity determinants are suppressors of transgene silencing in Nicotiana benthamiana. EMBO J 1998; 17: 6739-6746.

81. Ratcliff $F$, Harrison B, Baulcombe D. A similarity between viral defense gene silencing in plants. Science 1997; 276: 1558-1560.

82. Metzlaff M, O'Dell M, Cluster P, Flavell R. RNA-mediated RNA degradation and chalcone synthase A silencing in petunia. Cell 1997; 88: 845-854.

83. Parrish S, Fleenor J, Xu S, Mello C, Fire A. Functional anatomy of a dsRNA trigger: differential requirement for the two trigger strands in RNA interference. Mol Cell 2000; 6: 1077-1087.
84. Yang $\mathrm{D}$, Lu $\mathrm{H}$, Erickson J. Evidence that processed small dsRNAs may mediate sequencespecific mRNA degradation during RNAi in Drosophila embryos. Curr Biol 2000; 10: 1191-1200.

85. Tabara H, Sarkissian M, Kelly W, Fleenor J, Grishok A, Timmons L et al. The rde-1 gene, RNA interference, and transposon silencing in C. elegans. Cell 1999; 99: 123-132.

86. Tabara H, Hill R, Mello C, Priess J, Kohara Y. pos-1 encodes a cytoplasmic zinc-finger protein essential for germline specification in C. elegans. Development 1999; 126: 1-11.

87. Tabara H, Yigit E, Siomi H, Mello C. The dsRNA binding protein RDE-4 interacts with RDE-1, DCR-1, and a DExH-box helicase to direct RNAi in C. elegans. Cell 2002; 109: 861-871.

88. Green S, Mathews M. Two RNA-binding motifs in the double-stranded RNA-activated protein kinase, DAl. Genes Dev 1992; 6: 2478-2490.

89. Cox D, Chao A, Baker J, Chang L, Qiao D, Lin H. A novel class of evolutionarily conserved genes defined by piwi are essential for stem cell self-renewal. Genes Dev 1998; 12: 3715-3727.

90. Bohmert K, Camus I, Bellini C, Bouchez D, Caboche M, Benning C. AGO1 defines a novel locus of Arabidopsis controlling leaf development. EMBO J 1998; 17: 170-180.

91. Lynn K, Fernandez A, Aida M, Sedbrook J, Tasaka M, Masson P et al. The Pinhead/Zwille gene acts pleiotropically in Arabidopsis development and has overlapping functions with the Argonaute1 gene. Development 1999; 126: 469-481.

92. Zou C, Zhang Z, Wu S, Osterman J. Molecular cloning and characterization of a rabbit elF2C protein. Gene 1998; 211: 187-194.

93. Elmayan T, Balzergue S, Beon F, Bourdon V, Daubremet J, Guenet Y et al. Arabidopsis mutants impaired in cosuppression. Plant Cell 1998; 10: 1747-1758.

94. Cogoni C, Macino G. Isolation of quelling-defective [qde] mutants impaired in posttranscriptional transgene-induced gene silencing in Neurospora crassa. Proc Natl Acad Sci USA 1997; 94: 10233-10238.

95. Liu Q, Rand T, Kalidas S, Du F, Kim H, Smith D et al. R2D2, a bridge between the initiation and effector steps of the Drosophila RNAi pathway. Science 2003; 301: 1921-1925.

96. Catalanotto C, Azzalin G, Macino G, Cogoni C. Involvement of small RNAs and role of the qde genes in the gene silencing pathway in Neurospora. Genes Dev 2002; 16: 790-795.

97. Okamura K, Ishizuka A, Siomi H, Siomi M. Distinct roles for Argonaute proteins in small RNA-directed RNA cleavage pathways. Genes Dev 2004; 18: 1655-1666

98. Hamilton A, Baulcombe D. A species of small antisense RNA in posttranscriptional gene silencing in plants. Science 1999; 286: 950-952.

99. Tuschl T, Zamore $P$, Lehmann R, Bartel D, Sharp P. Targeted mRNA degradation by double-stranded RNA in vitro. Genes Dev 1999; 13: 3191-3197.

100. Hammond S, Bernstein E, Beach D, Hannon G. An RNA-directed nuclease mediates post-transcriptional gene silencing in Drosophila cells. Nature 2000; 404: 293-296.

101. Zamore P, Tuschl T, Sharp P, Bartel D. RNAi: double-stranded RNA directs the ATPdependent cleavage of mRNA at 21 to 23 nucleotide intervals. Cell 2000; 101: 25-33.

102. Bernstein E, Caudy A, Hammond S, Hannon G. Role for a bidentate ribonuclease in the initiation step of RNA interference. Nature 2001; 409: 363-366.

103. Elbashir S, Lendeckel W, Tuschl T. RNA interference is mediated by 21- and 22nucleotide RNAs. Genes Dev 2001; 15: 188-200.

104. Manche L, Green S, Schmedt C, Mathews M. Interactions between double-stranded RNA regulators and the protein kinase DAl. Mol Cell Biol 1992; 12: 5238-5248.

105. Elbashir S, Harborth J, Lendeckel W, Yalcin A, Weber K, Tuschl T. Duplexes of 21-nucleotide RNAs mediate RNA interference in cultured mammalian cells. Nature 2001; 411: 494-498.

106. Caplen N, Parrish S, Imani F, Fire A, Morgan R. Specific inhibition of gene expression by small double-stranded RNAs in invertebrate and vertebrate systems. Proc Natl Acad Sci USA 2001; 98: 9742-9747.

107. Winston W, Molodowitch C, Hunter C. Systemic RNAi in $C$. elegans requires the putative transmembrane protein SID-1. Science 2002; 295: 2456-2459.

108. Astier-Manifacier S, Cornuet P. RNA-dependent RNA polymerase in Chinese cabbage. Biochim Biophys Acta 1971; 232: 484-493.

109. Schiebel W, Haas B, Marinkovic S, Klanner A, Sanger H. RNA-directed RNA polymerase from tomato leaves. I. Purification and physical properties; II. Catalytic in vitro properties. J Biol Chem 1993; 268: 11851-11867.

110. Schiebel W, Pelissier T, Riedel L, Thalmeir S, Schiebel R, Kempe D et al. Isolation of an RNAdirected RNA polymerase-specific cDNA clone from tomato. Plant Cell 1998; 10: 2087-2101.

111. Cogoni C, Macino G. Gene silencing in Neurospora crassa requires a protein homologous to RNA-dependent RNA polymerase. Nature 1999; 399: 166-169.

112. Smardon A, Spoerke J, Stacey S, Klein M, Mackin N, Maine E. EGO-1 is related to RNAdirected RNA polymerase and functions in germ-line development and RNA interference in C. elegans. Curr Biol 2000; 10: 169-178.

113. Mourrain P, Beclin C, Elmayan T, Feuerbach F, Godon C, Morel J et al. Arabidopsis SGS2 and SGS3 genes are required for posttranscriptional gene silencing and natural virus resistance. Cell 2000; 101: 533-542.

114. Dalmay T, Hamilton A, Rudd S, Angell S, Baulcombe D. An RNAdependent RNA polymerase gene in Arabidopsis is required for posttranscriptional gene silencing mediated by a transgene but not by a virus. Cell 2000; 101: 543-553.

115. Sijen T, Fleenor J, Simmer F, Thijssen K, Parrish S, Timmons L et al. On the role of RNA amplification in dsRNA-triggered gene silencing. Cell 2001; 107: 465-476.

116. Vaistij F, Jones L, Baulcombe D. Spreading of RNA targeting and DNA methylation in RNA silencing requires transcription of the target gene and a putative RNA-dependent RNA polymerase. Plant Cell 2002; 14: 857-867.

117. Makeyev E, Bamford D. Cellular RNA-dependent RNA polymerase involved in posttranscriptional gene silencing has two distinct activity modes. Mol Cell 2002; 10 . 1417-1427. 
118. Alder M, Dames S, Gaudet J, Mango S. Gene silencing in Caenorhabditis elegans by transitive RNA interference. RNA 2003; 9: 25-32.

119. Nicolas F, Torres-Martinez S, Ruiz-Vazquez R. Two classes of small antisense RNAs in fungal RNA silencing triggered by non-integrative transgenes. EMBO J 2003; 22: 3983-3991.

120. Pak J, Fire A. Distinct populations of primary and secondary effectors during RNAi in C. elegans. Science 2007; 315: 241-244.

121. Sijen T, Steiner $F$, Thijssen K, Plasterk R. Secondary siRNAs result from unprimed RNA synthesis and form a distinct class. Science 2007; 315: 244-247.

122. Dougherty W, Parks T. Transgenes and gene suppression: telling us something new? Curr Opin Cell Biol 1995; 7: 399-405.

123. Grishok A, Tabara H, Mello C. Genetic requirements for inheritance of RNAi in C. elegans. Science 2000; 287: 2494-2497.

124. Vastenhouw N, Brunschwig K, Okihara K, Muller F, Tijsterman M, Plasterk R. Gene expression: long-term gene silencing by RNAi. Nature 2006; 442: 882 .

125. Park Y, Papp I, Moscone E, Iglesias V, Vaucheret H, Matzke A et al. Gene silencing mediated by promoter homology occurs at the level of transcription and results in meiotically heritable alterations in methylation and gene activity. Plant J 1996; 9: 183-194.

126. Lu R, Maduro M, Li F, Li H, Broitman-Maduro G, Li W et al. Animal virus replication and RNAi-mediated antiviral silencing in Caenorhabditis elegans. Nature 2005; 436: 1040-1043.

127. Wilkins C, Dishongh R, Moore S, Whitt M, Chow M, Machaca K. RNA interference is an antiviral defence mechanism in Caenorhabditis elegans. Nature 2005; 436: 1044-1047.

\section{Autobiography}

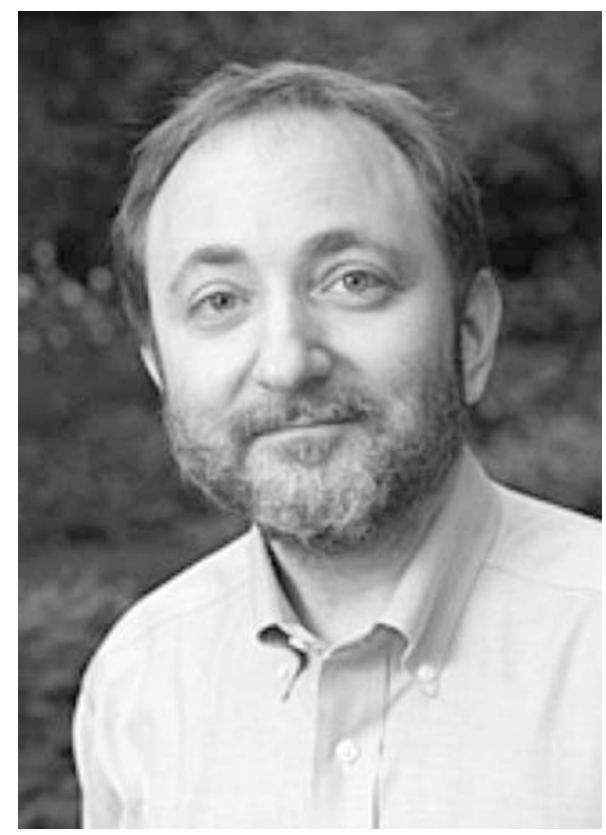

Andrew Zachary Fire was born on April 27, 1959 at Stanford University Hospital in Santa Clara County California. Spending most of his early years (until age 16) in nearby Sunnyvale, he attended the local public schools: Hollenbeck Elementary School (1964-1970), Mango Junior High School (19701972), and Fremont High School (1972-1975).

Fire enrolled at University of California at Berkeley in the Fall of 1975, receiving an AB degree in Mathematics in 1978. Fire then entered the PhD program in Biology at Massachusetts Institute of Technology as a National Science Foundation Fellow in the Fall of 1978. Fire's Ph.D. thesis, titled 'In Vitro Transcription Studies of Adenovirus', was submitted in 1983. From 1983 to 1986, Fire received training in the Caenorhabditis elegans group at the Medical Research Council Laboratory of Molecular Biology in Cambridge, England as a Helen Hay Whitney Foundation Fellow. During this time, Fire initiated research directed toward improvement of microinjection technology and development of assays for expression of foreign DNA in $C$. elegans worms.

During his last year at the MRC lab, Fire applied for a research position at the Carnegie Institution of Washington's Department of Embryology in Baltimore Maryland, also applying for an independent research grant 'Gene Regulation during early development of $C$. elegans' from the US National Institutes of Health. Both applications were successful and Fire moved to Baltimore in November of 1986. From his arrival at the Carnegie until 1989, Fire held the title of Staff Associate, an independent research position that was designed to facilitate the development of novel research programs in the absence of additional academic responsibilities. In 1989, Fire was appointed as a regular staff member at the Carnegie, with his group continuing to develop DNA transformation technology and collaborating on a number of studies to understand the molecular basis of gene activation in muscle cells. Along with the appointment as a full staff member at Carnegie Institution, Fire also acquired an adjunct appointment as a faculty member in the Department of Biology at Johns Hopkins, where he was involved in both graduate and undergraduate teaching and mentoring. In 2003, Dr Fire moved back to Santa Clara County, taking a position at the Stanford University School of Medicine, where he currently holds the title of Professor of Pathology and Genetics.

From Les Prix Nobel. The Nobel Prizes 2006, Editor Karl Grandin, [Nobel Foundation], Stockholm, 2007. Copyright (C) The Nobel Foundation 2006 